\title{
GUIA PARA
}

ELABORAÇÃO

DE PLANOS DE

DESENVOLVIMENTO

DE UNIDADES

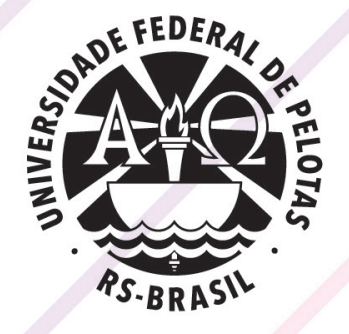




\section{UFPEL}

\section{Reitor:}

Pedro Rodrigues Curi Hallal

\section{Vice-Reitor:}

Luis Isaías Centeno do Amaral

Pró-Reitor de Planejamento e Desenvolvimento:

Otávio Martins Peres

\section{Coordenador de Desenvolvimento Institucional e Inserção Territorial: \\ Pedro Luís Machado Sanches}

\section{Chefe do Núcleo de Desenvolvimento Institucional:}

Claiton Leoneti Lencina

\section{Chefe do Núcleo de Inserção Territorial:}

Silvia Carla Bauer Barcellos

Equipe de redação (em ordem alfabética):

Andrews Dubois Jobim

Andria Caroline Angelo Santin

Bárbara Denise Xavier da Costa

Claiton Leoneti Lencina

Douglas Gadelha Sá

Joice Pereira da Silva Carvalho

Pedro Luís Machado Sanches

Dados Internacionais de Catalogação na Publicação: Bibliotecaria Patricia de Borba Pereira - CRB10/1487

\section{Comentários e sugestões (em ordem alfabética):}

Luiz Osório Rocha dos Santos

Otávio Martins Peres

Ricardo Zimmermann Fiegenbaum

Silvia Carla Bauer Barcellos

Simone Portella Teixeira de Mello

\section{Diagramação:}

Leonardo de Jesus Furtado

Realização:

Universidade Federal de Pelotas

U58g Universidade Federal de Pelotas

Guia para elaboração de planos para desenvolvimento de unidades/ Universidade Federal de Pelotas; Pró-Reitoria de Planejamento.- Pelotas: UFPEL, 2018.

$$
\text { 33p.: il. }
$$

ISBN - 978-85-7192-969-2

1. Universidade Federal de Pelotas.

2. Desenvolvimento Institucional. I. Título.

Pelotas, RS, 2018 


\section{PLANEJAMENTO EM PROCESSO NA UFPEL}

Tradicionalmente, as ações de Planejamento na UFPel ocorrem a partir da Administração Central, dirigidas para a base da comunidade acadêmica. Ainda são escassos os processos e meios que possibilitem o efetivo envolvimento de discentes, docentes e técnico -administrativos na gestão da informação e na tomada de decisão sobre as ações administrativas institucionais.

Como proposta efetiva para alterar esta realidade, que insiste em se perpetuar como contexto de administração centralizada, iniciativas têm sido propostas pela PROPLAN e pela Reitoria, voltadas à descentralização e ao pertencimento no Planejamento e no Desenvolvimento Institucional, com destaque para a constituição de um Conselho de Planejamento e a elaboração de Planos de Desenvolvimento das Unidades da UFPel.

São instrumentos e instâncias que visam a planejar da base para o topo, do fragmento para o conjunto, conectando e integrando as Unidades Acadêmicas à Administração Central, desburocratizando processos e mantendo plena atenção à inserção da UFPel no contexto social, político e cultural como instituição de vocação regional.

Sem minimizar a importância da Gestão Orçamentária e dos Projetos Infraestruturais, dimensões fundamentais para o funcionamento e a operação da Universidade, se cumpre agora a abertura de outras frentes: o planejamento do espaço institucional sensível às questões ambientais e cotidianas e à necessidade de compartilhamento; o desenvolvimento institucional multiescalar voltado para a integração política, cultural e cidadã; a inserção territorial a partir da interface com as cidades e instituições em projetos estratégicos e temas relevantes.

No presente documento propomos a elaboração de Planos de Desenvolvimento das Unidades no formato de um guia a ser apropriado, como um passo fundamental no processo de planejamento contínuo e participativo, considerando os reais interesses e movimentos pretendidos por quem efetivamente desempenha a atividade universitária acadêmica, cotidianamente imbuídos da formação de alunos, do desenvolvimento de pesquisas e linhas de inovação, das atividades de extensão e cultura e do atendimento às demandas administrativas descentralizadas da UFPel.

Convidamos a comunidade acadêmica a participar desta construção coletiva.

\section{Otavio Martins Peres}

Pró-Reitor de Planejamento e Desenvolvimento 


\section{SUMÁRIO}

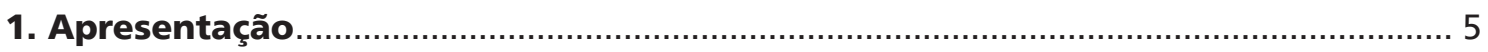

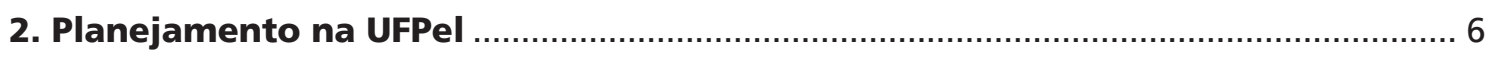

2.1 O Plano de Desenvolvimento Institucional da UFPel (PDI-UFPel 2015-2020) ................ 6

2.2 O Planejamento universitário nas Unidades Acadêmicas e Administrativas.................. 7

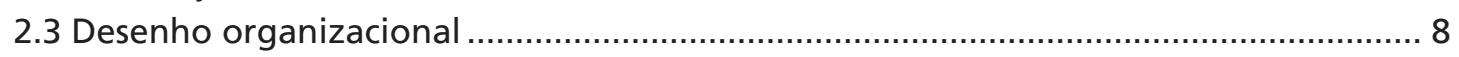

2.4 Memória dos instrumentos de planejamento da UFPel ............................................ 9

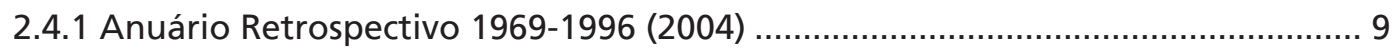

2.4.2 Planos de Ação e Avaliação (1998-2003) ............................................................ 10

2.4.3 Outros documentos relevantes (Decreto-Lei $n^{\circ} 750$ de 8 de agosto de 1969,

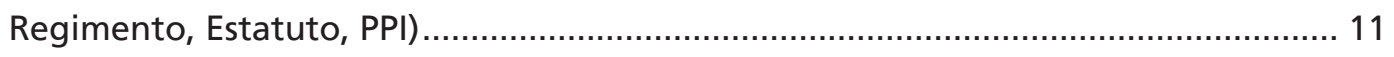

3. Estrutura do Plano de Desenvolvimento da Unidade (PDU) ................................. 13

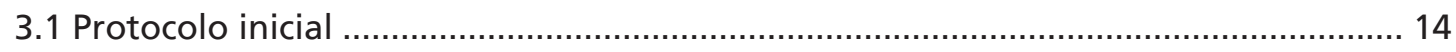

3.1.1 Capa

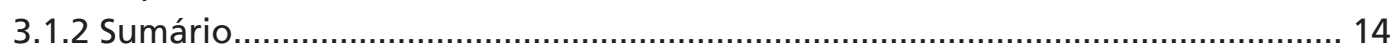

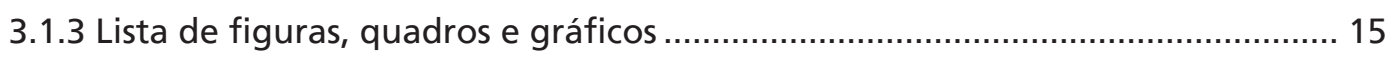

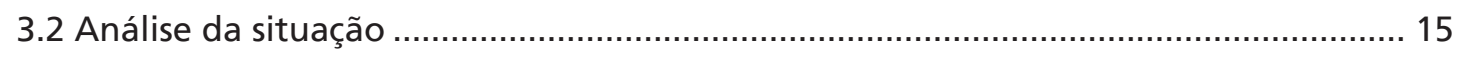

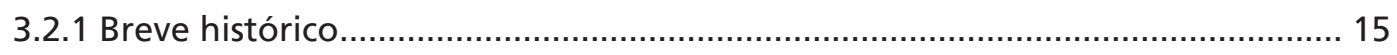

3.2.2 Rotinas e ferramentas de planejamento preexistentes..................................... 15

3.2.3 Contribuição da Unidade à Missão e à Visão da UFPel ....................................... 16

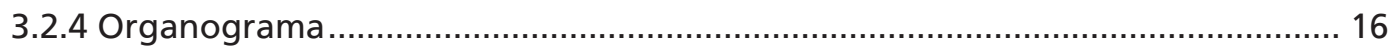

3.2.5 Perfil da comunidade (técnico-administrativos em educação, docentes, discentes

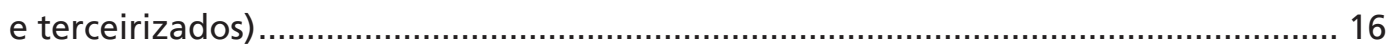

3.2.6 Levantamento da infraestrutura física ............................................................ 17

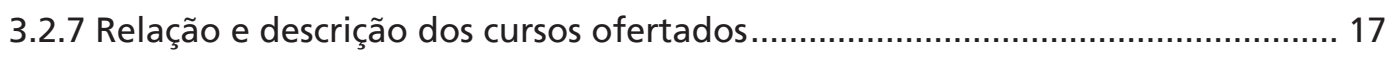

3.2.8 Relação dos projetos e programas (ensino, pesquisa, extensão, outros) ............ 18

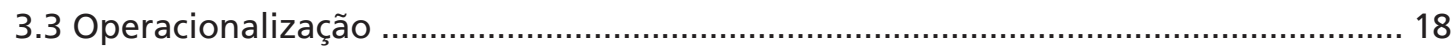

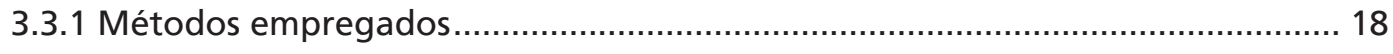

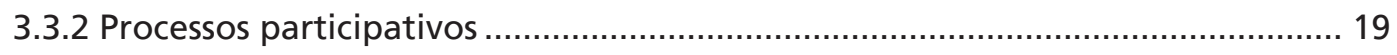

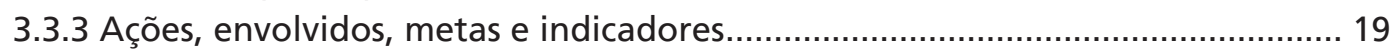

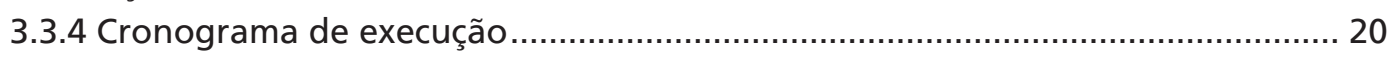

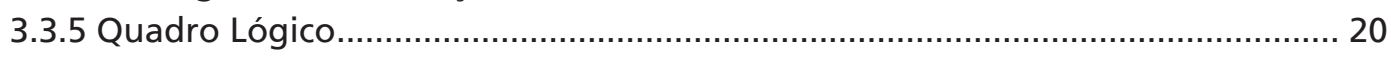

3.3.6 Meios de avaliação e de divulgação dos resultados ......................................... 21

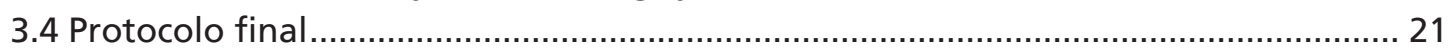

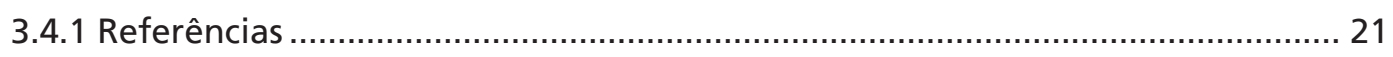

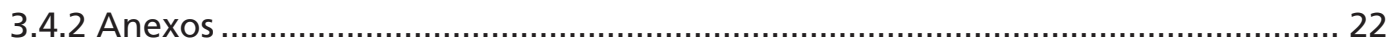

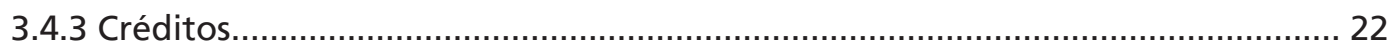

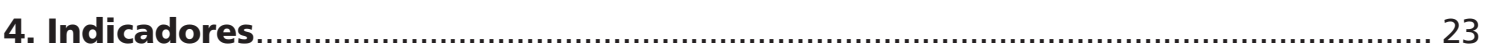

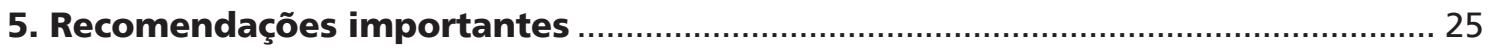

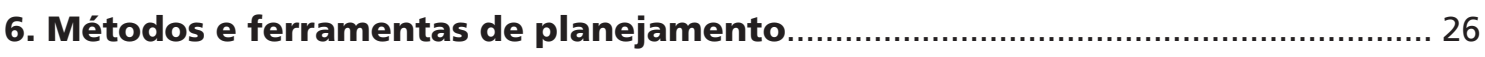

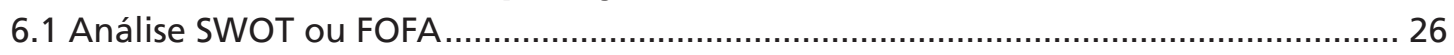

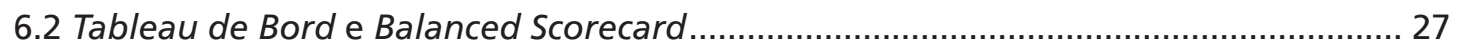

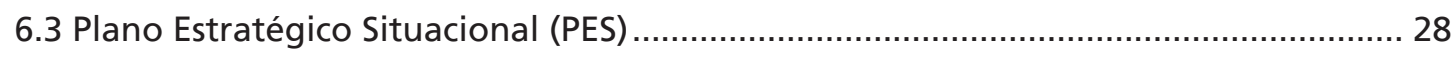

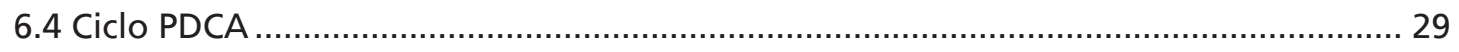

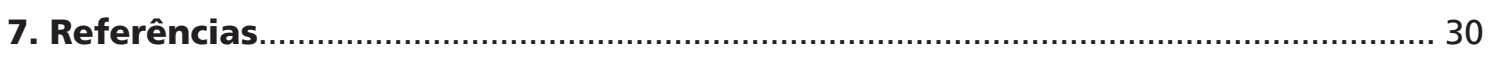

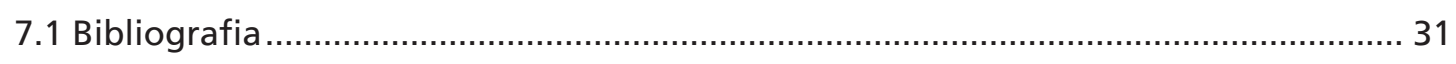

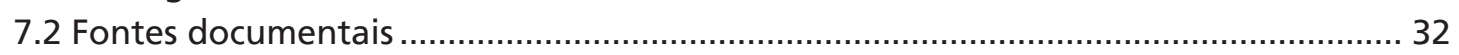




\section{Apresentação}

Nunca devemos nos esquecer de que o futuro não é nem totalmente nosso, nem
totalmente não nosso, para não sermos obrigados a esperá-lo como se estivesse por
vir com toda a certeza, nem nos desesperarmos como se não estivesse por vir jamais. Epicuro (341-270 a.C.) ${ }^{1}$

Este guia se destina a auxiliar a elaboração de Planos de Desenvolvimento das Unidades (PDUs), processo desencadeado em cada uma das Unidades Administrativas e Acadêmicas da UFPel e apoiado pela PROPLAN-UFPel. Sua apresentação se articula com os Seminários Temáticos "Criação Participativa do PDU", a serem realizados em espaços de grande circulação, junto às próprias Unidades.

A elaboração do PDU é uma importante oportunidade de reflexão sobre o papel da Unidade em relação à Universidade e à Sociedade, permite apresentar, avaliar e debater a situação atual, rever e propor inserções e compromissos sociais. Mas, a principal finalidade de se elaborar um PDU está em influir no futuro, em estabelecer caminhos para impactar a realidade, definindo e consolidando ações que possam ser desenvolvidas num período equivalente a dois anos, ou quatro semestres letivos.

Durante todo o processo de elaboração do PDU, o protagonismo é de quem integra a Unidade (alunos, professores e técnico-administrativos em educação). Cada comunidade acadêmica precisa se organizar para debater, redigir e aprovar seu próprio Plano, recorrendo aos meios de participação que melhor se adaptem às suas rotinas e costumes.

Cabe à PROPLAN sugerir um calendário de elaboração, acompanhar e apoiar a realização de suas etapas, fornecer dados e propor uma estrutura mínima para o documento a ser redigido. Esta estrutura, comum a todos os PDUs da UFPel, permitirá que eles estejam articulados com o Plano de Desenvolvimento Institucional (PDI) vigente na universidade, e sejam produzidos em consonância com diretrizes institucionais, sem maiores prejuízos ao potencial envolvimento da comunidade de cada Unidade ${ }^{2}$.

Discutidos e elaborados sob os mesmos critérios, mas de maneira independente, os 31 PDUs da UFPel (9 de Unidades Administrativas e 22 de Unidades Acadêmicas) permitirão identificar problemas, objetivos e interesses compartilhados, possibilitando o surgimento de uma cultura mais participativa e descentralizada de planejamento. Uma vez instituídos, os PDUs poderão aproximar Unidades Acadêmicas e Administrativas ao mesmo tempo em que registrarão anseios e necessidades de cada uma delas, apontando modos de agir e de avaliar reconhecidos e legitimados em consultas públicas e processos de participação.

Como nenhum outro documento, os PDUs promoverão um planejamento universitário integrado e ao alcance de toda a Universidade.

1 EPICURO 2002, p. 33.

2 A UFPel se organiza em Unidades Acadêmicas e Administrativas. Centros, Faculdades, Escolas e Institutos correspondem às unidades acadêmicas e realizam as atividades-fim da instituição. Pró-Reitorias e os Gabinetes do Reitor e do Vice-Reitor são unidades Administrativas e desempenham atividades-meio. Uma apresentação pormenorizada desta articulação está no item 2.3 - Desenho Organizacional. 


\section{Planejamento na UFPel}

Universidades são instituições hipercomplexas, habitadas por "portadores [e portadoras] de múltiplos projetos, com base em múltiplas racionalidades e exercendo, de forma ciosa, um alto grau de autonomia no seu cotidiano" ${ }^{3}$. Essa condição requer um planejamento universitário em múltiplas escalas e frentes de ação, configurando processos dinâmicos e abertos que levem em conta diferentes análises da situação, sem perder de vista a necessidade de pactuar em prol de objetivos comuns. Assim, boa parte do sucesso de ações de planejamento nas universidades depende do efetivo envolvimento de uma grande diversidade de atores e atrizes na definição de estratégias, táticas, ações e metas de desenvolvimento.

Embora distantes do cotidiano da maioria da comunidade acadêmica, algumas ferramentas de planejamento estiveram e estão em vigência na UFPel. Procurando não omitir o que já existe ou existiu, abaixo são apresentados sinteticamente os principais instrumentos de planejamento da UFPel, enfatizando a relação que possam ter com a descentralização de decisões e ações, objetivo principal do esforço atual de elaboração de Planos de Unidades.

\subsection{O Plano de Desenvolvimento Institucional da UFPel (PDI-UFPel 2015-2020)}

O Plano de Desenvolvimento Institucional (PDI) vigente na UFPel (disponível em http://wp.ufpel.edu.br/scs/pdi/) é o documento que apresenta a visão de futuro e os objetivos estratégicos comuns a todas as Unidades da Universidade. Este plano, em vigor desde 2015, se destina à construção coletiva da instituição, lhe cabendo traduzir em estratégias e metas as ideias, necessidades e desejos de toda a UFPel.

O PDI atual tem vigência até o ano de 2020 e está organizado em cinco grandes temas: 1. gestão institucional; 2. gestão acadêmica (ensino, pesquisa e extensão); 3 . assistência estudantil, 4. gestão de pessoas e 5 . infraestrutura.

Assim como o Estatuto e o Regimento Geral da UFPel, ou o Projeto Pedagógico Institucional (PPI), o PDI deve estar articulado com as práticas e métodos de gestão pública, avaliações, indicadores e demais meios administrativos adotados. O PDI deve estar presente, inclusive, nos debates e reflexões sobre a situação atual da instituição.

Planos de Desenvolvimento das Unidades (PDUs) estão entre os muitos objetivos específicos do $\mathrm{PDI}^{4}$, e sua importância se baseia no papel desempenhado pelas Unidades Acadêmicas e Administrativas na efetivação da missão institucional da UFPel, na plena realização das atividades-fim da Universidade.

Ações futuras planejadas pelas Unidades, e a maneira como tais ações serão planejadas, precisam se articular com os objetivos do PDI, sendo sensíveis às suas estratégias, por um lado, influindo e fundamentando seus desdobramentos futuros, por outro. Assim, as prioridades que as Unidades pretendam estabelecer por meio de seus PDUs podem se alinhar aos 5 grandes temas do PDI expostos acima, constituindo valiosas relações, sobretudo em dois aspectos:

a. Possibilitam uma ampla e aprofundada discussão dentro da Unidade sobre os rumos a serem tomados por toda a instituição;

3 CECILIO 2001, p. 5.

4 O quinto objetivo do tema Gestão Institucional do PDI UFPel 2015-2020 (p. 10) prevê que sejam instituídos "planos de desenvolvimento das Unidades Acadêmicas e Administrativas alinhados ao PDI". 
b. Permitirão que os PDUs sirvam de base para o processo de elaboração do próximo PDI da UFPel, a ser concluído até o final do ano de 2020.

\subsection{O Planejamento universitário nas Unidades Acadêmicas e Administrativas}

A UFPel é uma Universidade pública e gratuita, organizada em estrutura multicampi situada nos municípios de Pelotas e Capão do Leão, com um polo presencial em Eldorado do Sul, além de polos de ensino a distância em vários municípios do Rio Grande do Sul e demais estados da região Sul do Brasil ${ }^{5}$.

Apenas no município de Pelotas, são 6 os Campi da UFPel com estrutura física integrada à cidade, de modo a compartilhar muitas de suas características, favoráveis ou desfavoráveis. Esta condição difere muito da encontrada no Campus Capão do Leão, ou no Centro Agropecuário da Palma, distantes de aglomerações urbanas ${ }^{6}$ e caracterizados por uma grande área contínua integralmente dedicada às atividades-fim da Universidade.

Tamanha diversidade de configurações, e a grande profusão de ambientes que the corresponde, tornam o planejamento de uma Instituição de Ensino Superior como a UFPel um grande desafio. Em tais circunstâncias, descentralizar a produção de planos de desenvolvimento é um modo de garantir que problemas sejam identificados, ações sejam definidas, e meios sejam mobilizados na base, por aquelas pessoas que têm vivência cotidiana da Unidade, se responsabilizam pelo seu desenvolvimento institucional e, consequentemente, estão aptas a estabelecer prioridades e definir caminhos. O envolvimento destas pessoas, protagonistas de um planejamento solidário e inclusivo, assegura legitimidade e viabilidade ao processo.

De modo geral, é possível dizer que o planejamento possui três dimensões: a estratégica, a tática e a operacional. A dimensão estratégica estabelece um horizonte amplo e de longa duração para mudanças na instituição como um todo. Por isso, se insere nessa dimensão a definição de eixos temáticos e objetivos estratégicos. Na UFPel, eles estão reunidos no PDI 2015-2020.

A dimensão tática é aquela que corresponde à definição de caminhos possíveis e viáveis para transformar a realidade, o que implica em não perder de vista os objetivos estratégicos, mas também em considerar as variáveis inerentes à gestão da instituição e às circunstâncias políticas, econômicas e sociais existentes, reavaliando constantemente as condições para realizar o que foi planejado.

Por sua vez, a dimensão operacional está relacionada às ações específicas de desenvolvimento, voltadas à plena realização das atividades-fim por meio da aplicação direta dos recursos humanos, infra-estruturais e orçamentários.

No planejamento de uma instituição como a UFPel, é compreensível que tanto os PDUs das Unidades acadêmicas, quanto os PDUs das administrativas sejam tático-operacionais, mas haverá diferenças quanto à ênfase dada a cada uma dessas dimensões em cada Unidade.

5 Os polos de ensino à distância da UFPel no Rio Grande do Sul se situam nos municípios de Agudo, Arroio dos Ratos, Balneário Pinhal, Cacequi, Cachoeira do Sul, Cerro Largo, Camargo, Constantina, Cruz Alta, Encantado, Esteio, Herval, Hulha Negra, Jacuizinho, Jaguarão, Jaquirana, Mostardas, Novo Hamburgo, Panambi, Picada Café, Quaraí, Restinga Seca, Rosário do Sul, Santa Vitória do Palmar, Santana da Boa Vista, Santana do Livramento, Santo Antônio da Patrulha, São João do Polêsine, São Francisco de Paula, São José do Norte, São Lourenço do Sul, Sapiranga, Sapucaia do Sul, São Sepé, Seberi, Serafina Corrêa, Sobradinho, Três de Maio, Três Passos e Vila Flores. No estado de Santa Catarina há um pólo na cidade de Videira. No Paraná, dois pólos, um em Paranaguá e outro em Ibaiti. 6 Ambos situados no município de Capão do Leão, emancipado de Pelotas em 1982. 
À primeira vista, parece existir uma direção única ou uma hierarquia entre as dimensões estratégica, tática e operacional. Esta relação se reflete inclusive nos instrumentos e setores que respondem por cada uma das dimensões. Atualmente, na UFPel, seria possível representá-la pela pirâmide azul (figura 1, à esquerda). Mas os PDUs serão documentos importantes também para subsidiar a elaboração do próximo PDI da UFPel, e para informar à Administração Universitária sobre os rumos que cada Unidade pretende seguir. Assim, os PDUs servirão de fundamento para novas táticas e futuras estratégias comuns a toda a instituição, o que corresponde a uma inversão da pirâmide (figura 1, à direita), e ao estabelecimento de um novo ciclo de planejamento, previsto para se iniciar em 2021.
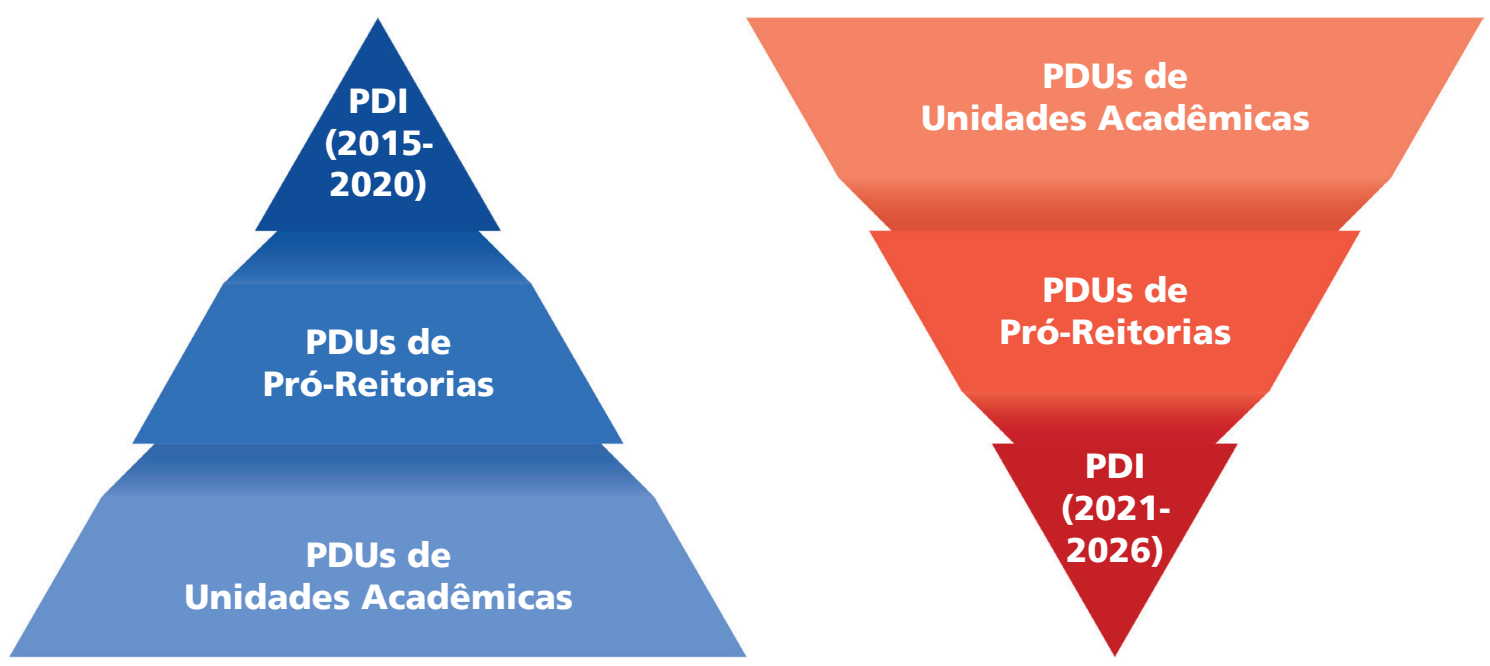

Figura 1 - Inversão na pirâmide do planejamento institucional na UFPel

Envolver as comunidades acadêmicas, em toda a sua diversidade, é um pressuposto para que o planejamento universitário seja uma prática responsável, horizontal, socialmente referenciada e presente no cotidiano de toda a UFPel.

\subsection{Desenho organizacional}

O desenho organizacional atual da UFPel se compõe de 10 Unidades Administrativas e 22 Unidades Acadêmicas. As Pró-reitorias e os Gabinetes do reitor e do vice-reitor são Unidades Administrativas, enquanto as atividades-fim da instituição (ensino superior, pesquisa científica e extensão universitária) são responsabilidade das Unidades Acadêmicas. Estas podem ser Faculdades, Escolas, Institutos ou Centros, e podem se compor apenas de colegiados de curso, ou conter também departamentos.

Tanto as Unidades Acadêmicas, quanto as Administrativas, possuem estruturas internas de decisão e órgãos suplementares que cumprem papel fundamental em seu funcionamento. Todas essas estruturas, suas vinculações e relações, podem ser apresentadas na forma de organograma?

A estrutura administrativa da UFPel tem uma história marcada por sucessivas incorporações e reestruturações, o que permite entender, em parte, sua heterogeneidade.

Qualquer organização existente pode se revelar incapaz de atender plenamente os

7 Cabe a cada Unidade formular seu organograma interno. Recomenda-se que este organograma e eventuais propostas de alteração surgidas no processo de elaboração possam ser incluídas no PDU (como orienta, a seguir, o item 3.2.4 Organograma). Alterações no desenho organizacional requerem aprovação em Conselho Universitário e múltiplas adequações. 
objetivos acadêmicos, científicos e sociais de cada Unidade, sendo recomendável a sua revisão toda vez que se mostrar ineficiente ou incompatível às necessidades e anseios da comunidade.

\subsection{Memória dos instrumentos de planejamento da UFPel}

Desde suas origens, as ações de planejamento e desenvolvimento institucional da UFPel têm se mostrado descontínuas, pouco efetivas e pouco abrangentes.

O primeiro Plano de Desenvolvimento da UFPel foi elaborado no quadriênio 1983$1986^{8}$, e as iniciativas de planejamento que lhe sucederam se organizavam nos mesmos cincos grandes temas do PDI atual (gestões institucional, acadêmica e de pessoas, assistência estudantil e infraestrutura).

A aplicação de instrumentos de planejamento na UFPel, entre meados dos anos 1980 e os primeiros anos do século XXI, registram avanços em relação à estrutura física e às atividades acadêmicas. Muitas vezes, planos, rotinas e levantamentos de dados deste período envolveram consultas à direção das Unidades. Formalmente, se destinavam a orientar o desenvolvimento da Universidade em momentos decisivos de sua existência, como a redemocratização e a implantação de novas políticas públicas.

Neste período, "estratégias, planos e técnicas mais eficientes do que os procedimentos institucionais dos governos autoritários" 9 foram aprofundados e acelerados nas Universidades Brasileiras, o que contou com a concordância interna.

Documentos publicados e o relato de quem participou de sua elaboração, aplicação e avaliação permitem trazer para este guia um breve panorama das ações de planejamento que já tiveram lugar na instituição. Diante das peculiaridades do momento atual, marcado por escassez orçamentária e instabilidade política, a consideração dessa memória administrativa pode ser útil, permite rever e reavaliar experiências, refletir sobre potencialidades e limites, ou sobre o enfrentamento de adversidades por meio de ações de planejamento.

\subsubsection{Anuário Retrospectivo 1969-1996 (2004)}

No ano de 2004 foram publicados três volumes de um Anuário Retrospectivo da UFPel. O documento procurou compilar dados e informações referentes ao desenvolvimento da Universidade em seus 27 primeiros anos de funcionamento. Norteado pelo ideal de que compreender a situação presente é condição para o correto e amplo conhecimento do passado, aquele Anuário plurianual apresentou gráficos, dados estatísticos e textos que se prestavam a apontar progressos e limitações, num retrospecto das principais tendências do desenvolvimento institucional em cada período.

Além de se apresentar como ferramenta de planejamento, o Anuário pretendeu informar a população externa sobre os resultados obtidos em quase três décadas de presença da UFPel na Zona Sul do Estado. Traz dados relativos ao ensino, à pesquisa e à extensão, além de abordar estruturas de planejamento, administração, orçamento e pessoal, especificando particularidades de cada domínio.

8 Apud ANUÁRIO RETROSPECTIVO DA UFPel 1969/1996. Universidade Federal de Pelotas. Pró-Reitoria de Planejamento e Desenvolvimento. - Pelotas: Departamento de Desenvolvimento Institucional, 2004.

9 SILVA 2014, p. 43. 
A principal fonte de informações apontada no Anuário é o Núcleo de Documentação Histórica da UFPel criado em 1990 e dotado de grande acervo documental acerca da Universidade, além de importantes documentos sobre a cidade de Pelotas e a Região Sul.

\subsubsection{Planos de Ação e Avaliação (1998-2003)}

Este par de documentos tinha como base as demandas advindas dos setores acadêmicos e administrativos. Abrangia o desenvolvimento de cada uma das Unidades da UFPel, mas também sua influência externa (desenvolvimento regional, Mercosul, dentre outras). A primeira versão dos Planos de Ação e Avaliação data de 1998, e sua última edição completa se deu entre 2003 e 2004. O planejamento por articulação entre plano e avaliação tinha duração de um ano inteiro, e previa a aplicação de dois instrumentos:

Planos de Ação eram elaborados cerca de um ano antes de sua execução, por meio de formulários em disquetes enviados pela Pró-Reitoria de Planejamento a todas as Unidades. Em cada Unidade, o(a) diretor(a), vice-diretor(a), chefes de departamentos, coordenadores(as) de colegiado, e representantes dos discentes e dos técnico-administrativos, se reuniam para discutir o que seria colocado em pauta no planejamento daquele ano. A Pró -Reitoria de Planejamento auxiliava quando necessário e, assim que as disquetes retornavam à Pró-Reitoria, os dados eram compilados e inseridos num só documento, comum a toda a Universidade. Nos últimos anos de sua aplicação, os Planos puderam ser preenchidos online, até deixarem de existir na UFPel em 2004 ${ }^{10}$.

No decorrer de sua curta existência, os Planos de Ação passaram por modificações significativas. A primeira edição (1998), trazia dez planos com metas próprias, englobando diferentes ações. Cinco anos depois, na última edição de um Plano de Ação da UFPel (2003/2004), os dez planos deram lugar a programas, com objetivos gerais, enquanto as ações foram divididas em "atividades", que não possuíam previsão de término, e "projetos", com duração pré-determinada.

A Avaliação de cada Plano de Ação era feita no final do ano, para que pudesse servir de base à elaboração do próximo Plano de Ação. As Unidades elaboravam suas avaliações, depois compiladas pela Pró-Reitoria, repetindo o expediente dos próprios Planos. Cada Avaliação continha um parecer final de uma comissão, verificando o cumprimento dos objetivos.

Um aspecto importante do planejamento por Planos de Ação e Avaliação é a ênfase que davam a uma concepção de planejamento multifacetado, reunindo demandas e metas definidas por representantes de cada Unidade. A publicação do Plano em um só volume permitia uma consulta rápida das ações planejadas por toda a Universidade para o ano seguinte, o que favorecia uma visão de conjunto dos rumos da instituição. A transparência na tomada de decisões e uma maior cobrança de compromissos assumidos podem ter sido favorecidos por esse tipo de Plano.

10 Informações geradas em entrevista com Milton Luís Bresque Rodrigues, em 20 de julho de 2017. 


\subsubsection{Outros documentos relevantes (Decreto-Lei $n^{\circ} 750$ de 8 de agosto de 1969, Regimento, Estatuto, PPI)}

Os quatro documentos aqui apresentados abordam o papel da UFPel perante a comunidade interna e externa à época em que foram redigidos. Muito do que afirmam foi atualizado mediante resoluções dos conselhos da UFPel, ao longo de décadas.

O Decreto-lei $n^{\circ} 750$, de 8 de agosto de 1969, cria a UFPel nos moldes da lei durante o período ditatorial militar, num contexto de restrição de liberdades políticas agravada pela recente instauração do Ato Institucional $n^{\circ} 5$.

A UFPel nasceu do agrupamento de órgãos de ensino superior situados em Pelotas que, até então, faziam parte da Universidade Federal Rural do Rio Grande do Sul e da Universidade Federal do Rio Grande do Sul, além de instituições particulares. Este arranjo pode ser relacionado à Reforma Universitária em curso na época (lei $n^{\circ} 5.540$, de 28 de novembro de 1968).

O Estatuto e o Regimento da UFPel foram homologados em 1977, são documentos que tratam de "aspectos gerais e comuns da estrutura e funcionamento dos órgãos, serviços e atividades da Universidade Federal de Pelotas" (Regimento, art. $1^{\circ}$ ). Grande parte da redação do Estatuto é repetida literalmente no Regimento, mas, enquanto o Estatuto é generalista e sucinto, o Regimento apresenta os mesmos aspectos pormenorizadamente.

Estatuto e Regimento afirmam o caráter público da UFPel, a existência, composição e finalidade de seus três conselhos superiores, e objetivos embasados na "natureza orgânica, social e comunitária" da instituição, estabelecendo o tripé ensino-pesquisa-extensão. Um organograma geral da Universidade é apresentado, dividido entre a administração superior, unidades universitárias, órgãos suplementares e órgãos de "segundo grau" (reunidos no Conjunto Agrotécnico Visconde da Graça, desvinculado da UFPel em 2010).

O Regimento sistematiza as diversas modalidades de curso (graduação, pós-graduação, extensão, especialização e aperfeiçoamento), estruturas administrativas, órgãos e definições gerais. Estabelece a organização dos colegiados de curso e da pesquisa científica, e dispõe sobre vários processos, desde matrícula, reopção e transferência, até a elaboração do calendário acadêmico e a seleção de servidores. O Regimento afirma, por exemplo, que é "obrigatória a realização de concurso público", e institui a união entre ensino e pesquisa na prática docente. Trata também de estabilidade, aposentadoria, dentre outros temas, e, em sua parte final, aborda disposições gerais e transitórias como, por exemplo, o empate em eleições docentes e discentes.

O Projeto Pedagógico Institucional da UFPel foi elaborado em 1991 e atualizado em 2003. Anterior ao Programa de Apoio a Planos de Reestruturação e Expansão das Universidades Federais (o REUNI), e à adesão da UFPel ao Sistema de Seleção Unificado (o SISU), este documento registra a preocupação em definir a inserção social da UFPel, se destinando a nortear e aperfeiçoar o ensino superior por meio de cinco princípios: "a) o compromisso da universidade pública com os interesses coletivos; b) a indissociabilidade entre o ensino, pesquisa e extensão; c) o entendimento do processo de ensino-aprendizagem como multidirecional e interativo; d) o respeito às individualidades inerentes a cada aprendiz; e) a importância da figura do professor como basilar na aplicação de novas tecnologias". A missão da Universidade, objetivos pedagógicos e o perfil dos cursos existentes são temas do Projeto Pedagógico, mas o documento é importante, sobretudo, por registrar anseios do corpo técnico, docente e discente. Ao apontar táticas, metodologias e feições dos cursos, instrumen- 
tos e modalidades de ensino, não deixa de lado as utopias próprias do ensino superior.

Vale lembrar que uma Constituinte Universitária foi instituída em 2013 com a finalidade de rever e atualizar o Estatuto, o Regimento e o Projeto Pedagógico Institucional da UFPel. Representantes das três categorias devem fazer parte desse processo que objetiva tornar a UFPel "(...) uma Universidade sincronizada com o seu tempo e sintonizada com o desenvolvimento sustentável da sociedade"11.

Informações sobre o processo de atualização desses documentos por meio da Estatuinte Universitária podem ser encontradas em http://wp.ufpel.edu.br/constituinte/.

11 Informações disponíveis em: http://wp.ufpel.edu.br/constituinte/pagina-exemplo/. 


\section{Estrutura do Plano de Desenvolvimento da Unidade (PDU)}

O PDU possibilita às comUnidades Acadêmicas e Administrativas a expressão de seus anseios para o futuro próximo, e a pactuação de metas para o desenvolvimento institucional, estabelecendo os papéis de cada envolvido(a) no alcance dessas metas. Se, por um lado, prevê ampla participação nas decisões de planejamento e na definição de prioridades, por outro, permite a qualquer pessoa interessada, de dentro ou de fora da instituição, saber que rumos a Unidade pretende tomar.

A elaboração do PDU deve contar com a participação de integrantes de todas as categorias (discente, docentes e técnico-administrativos em educação), recorrendo, para isso, aos meios de comunicação e deliberação que melhor se adaptem ao cotidiano da Unidade, e permitam a ampla discussão e a definição de ações, metas e prioridades ${ }^{12}$.

Ao tornar público seu próprio planejamento, cada Unidade evidenciará de que forma pretende contribuir com o planejamento da UFPel como um todo, estabelecendo quais objetivos estratégicos e ações do PDI em vigor serão priorizados pela Unidade durante os dois anos ou quatro semestres letivos de execução do PDU. Nesse tempo, o que foi planejado deve ser realizado e avaliado, considerando as ações e metas definidas de modo participativo. A reflexão sobre os resultados obtidos servirá de base para a elaboração do PDU seguinte, instituindo um novo ciclo de planejamento.

Alguns tópicos precisam fazer parte de todos os PDUs. Eles visam a uma apresentação nítida das características da Unidade e de seus planos para o futuro, priorizando problemas que possam ser enfrentados e avaliados pela própria comunidade acadêmica ou administrativa.

A análise da situação registrada no PDU é constituída de breve histórico, levantamentos de rotinas administrativas, infraestrutura, cursos e projetos, dados acerca do corpo discente e do quadro de servidores. Mas, o PDU não é somente analítico, também indica o que pode ser feito para melhorar e ampliar as atividades da Unidade, sua relação com a Sociedade, bem como sua interação e integração com outros setores da Universidade, o que corresponde à operacionalização do Plano, sua parte propositiva.

Para facilitar a localização e o cotejo de informações, os PDUs da UFPel terão uma Parte Analítica e uma Parte Propositiva articuladas e estruturadas de acordo com os elementos textuais apontados no quadro abaixo:

12 Ver o item 3.3.2 Processos participativos. 
Estutura Elementar dos PDUs da UFPel (versão 2018-2020)

\begin{tabular}{|c|c|}
\hline Elementos Pré-textuais & $\begin{array}{l}\text { PROTOCOLO INICIAL } \\
\text { - Capa; } \\
\text { - Sumário; } \\
\text { - Lista de figuras, quadros e gráficos. } \\
\end{array}$ \\
\hline Parte Analítica do PDU & $\begin{array}{l}\text { ANÁLISE DA SITUAÇÃO } \\
\text { - Breve histórico; } \\
\text { - Rotinas e ferramentas de planejamento preexistentes; } \\
\text { - Contribuição à Missão e à Visão da UFPel; } \\
\text { - Organograma; } \\
\text { - Relação e descrição dos Cursos Ofertados; } \\
\text { - Perfil da Comunidade; } \\
\text { - Levantamento da Infraestrutura Física; } \\
\text { - Projetos e Programas. }\end{array}$ \\
\hline Parte Propositiva do PDU & $\begin{array}{l}\text { OPERACIONALIZAÇÃO } \\
\text { - Metodologia(s) adotada(s); } \\
\text { - Processos participativos; } \\
\text { - Ações, envolvidos, metas e indicadores; } \\
\text { - Cronograma de execução; } \\
\text { - Quadro Lógico; } \\
\text { - Meios de avaliação e divulgação dos resultados. }\end{array}$ \\
\hline Elementos Pós-textuais & $\begin{array}{l}\text { PROTOCOLO FINAL } \\
\text { - Bibliografia; } \\
\text { - Anexos; } \\
\text { - Créditos. }\end{array}$ \\
\hline
\end{tabular}

Esta estrutura proposta se refere a um mínimo de informações necessárias ao planejamento institucional como um todo, ficando cada Unidade livre para acrescentar o que julgar necessário, e o que melhor se aplique à sua realidade.

A seguir, serão comentados e apresentados em pormenor os tópicos elementares do PDU, considerando o que cada um deles deve abranger.

\subsection{Protocolo inicial}

\subsubsection{Capa}

A Unidade pode conceber a capa de seu PDU como queira, constituindo uma identidade visual própria para suas ações de planejamento. Necessário será constar a expressão "Plano de Desenvolvimento da Unidade", a sigla "PDU", o nome e a sigla da Unidade, o nome e a sigla da UFPel, e o período de vigência do Plano. Recomenda-se que a data e o local da publicação do PDU, assim como as logomarcas da Unidade e da UFPel também sejam incluídas.

\subsubsection{Sumário}

Corresponde a uma lista ordenada dos capítulos, subcapítulos e outras divisões textuais, na sequência em que se apresentam no decorrer do texto, com indicação do número da primeira página de cada item. 


\subsubsection{Lista de figuras, quadros e gráficos}

Listagem de todos os elementos ilustrativos de apoio ao texto, indicando as páginas em que se encontram, conforme Manual de Normas da UFPel ${ }^{13}$.

\subsection{Análise da situação}

Os tópicos desta parte do PDU se prestam a registrar aquilo que, de alguma forma, já existe. Projeções, anseios, demandas e necessidades serão expostas na Parte Propositiva do PDU, no item 3.3.3 Ações, envolvidos, metas e indicadores.

\subsubsection{Breve histórico}

Neste tópico deve ser feita uma síntese da história da Unidade, contendo informações sobre a constituição de seu perfil institucional, e relatos acerca das principais ações que marcaram seu passado.

Trata-se de uma exposição sobre a trajetória da Unidade e seu desenvolvimento organizacional, na qual é preciso pontuar os momentos em que se deu a criação e a extinção de cargos, setores ou cursos, substituições, ampliações e adequações do espaço físico, mudanças significativas no quadro de servidores, no número de alunos, ou no público externo atendido.

O Breve Histórico pode conter alusões a convênios e acordos firmados, bem como delinear transformações e eventos que tenham marcado a história da Unidade.

\subsubsection{Rotinas e ferramentas de planejamento preexistentes}

Caso a Unidade não disponha de rotinas e ferramentas de planejamento, esta informação deve ser explicitada neste item do PDU.

Quaisquer rotinas e ferramentas de planejamento implantadas na Unidade precisam ser descritas neste tópico.

Pesquisas de opinião, quadros de ações, planos de gastos ou levantamentos sócio-econômicos são exemplos recorrentes de instrumentos que podem ter sido empregados no planejamento de uma Unidade. Ao apresentá-los, é importante informar como cada instrumento contribuiu para o alcance de metas e objetivos. Sempre que possível, e quando for o caso, é importante apresentar as razões que levaram à descontinuidade da aplicação de tais rotinas e ferramentas.

Não é preciso anexar nenhum instrumento de planejamento pré-existente ao PDU, mas é recomendável a inclusão de resultados obtidos por meio deles, em gráficos, tabelas ou comentários e pareceres pontuais.

13 Disponível em <http://wp.ufpel.edu.br/sisbi/normas-da-ufpel-para-trabalhos-academicos/>. Em caso de dúvida, é possível considerar as normas estabelecidas pela ASSOCIAÇÃO BRASILEIRA DE NORMAS TÉCNICAS (NBR 14724: Informação e documentação - Trabalhos acadêmicos - Apresentação. Rio de Janeiro: Abnt, 2006). 


\subsubsection{Contribuição da Unidade à Missão e à Visão da UFPel}

A Unidade deve declarar, com nitidez e precisão, qual é a sua contribuição para a concretização da Missão da UFPel, e de que modo se relaciona com a Visão da UFPel. Ambas estão disponíveis em http://portal.ufpel.edu.br/missao-visao/.

O registro de debates e comentários acerca da Missão e da Visão da UFPel surgidos no decorrer da elaboração do PDU podem ser incluídos nesse item.

\subsubsection{Organograma}

De modo sucinto, a atual estrutura administrativa da Unidade precisa ser apresentada. Direção, coordenações, colegiados, departamentos, suas inter-relações e subdivisões precisam constar no PDU. Para tanto, recomenda-se a elaboração de um organograma.

Propostas de alteração no organograma atual, tais como a criação ou extinção de subunidades e cargos, podem ser mencionadas e comentadas neste tópico, mas toda mudança na organização administrativa prevista para o próximo biênio precisa figurar no quadro de ações, envolvidos, metas e indicadores (item 3.3 .3 a seguir).

\subsubsection{Perfil da comunidade (técnico-administrativos em educação, docentes, dis- centes e terceirizados)}

Será preciso caracterizar a comunidade interna de forma resumida, apontando aspectos socio-econômicos e culturais que se mostrem relevantes para compreender a inserção de cada categoria na Unidade, inclusive a dos professores temporários, e a dos trabalhadores terceirizados.

As informações deste tópico podem ser acompanhadas de tabelas ${ }^{14}$, mas não devem nomear ou tratar de problemas relativos à inserção profissional.

Importa observar que o Perfil da Comunidade não deve favorecer práticas persecutórias de nenhuma natureza. O Perfil priorizará dados quantitativos referentes à coletividade, preservando a identidade dos envolvidos ao mesmo tempo em que permitirá levantar carências de capacitação, dimensionar a força de trabalho nos diferentes setores, e justificar ações a serem implementadas em curto prazo.

No que diz respeito aos técnicos administrativos em educação, importa indicar sua distribuição nos setores da Unidade (quantos técnicos se encontram vinculados a cada setor), quantificar os técnicos afastados e a data prevista de seu retorno, e apontar o quantitativo dos níveis de qualificação (nível médio, superior, pós-graduação). Outras informações consideradas relevantes podem ser incluídas, como a carência de técnicos com determinado perfil, mas qualquer previsão de mudança no quadro técnico precisa figurar no item 3.3.3 Ações, envolvidos, metas e indicadores.

A apresentação do perfil do corpo docente deve se dar nos mesmos moldes do perfil do corpo técnico-administrativo. Do mesmo modo, é possível relatar eventuais desafios

14 Considerando dados quantitativos fornecidos pela Coordenação para o Desenvolvimento Institucional e a Inserção Territorial da Pró-Reitoria de Planejamento e Desenvolvimento da UFPel (CDIT-PROPLAN) e revisados pela própria Unidade. Maiores informações e contato: http://wp.ufpel.edu.br/proplan/cdit/. 
relacionados ao regime de trabalho e ao dimensionamento da força de trabalho docente, observando a indissociabilidade entre ensino, pesquisa e extensão universitária, podendo abranger também o revezamento em funções administrativas internas.

A quantificação de professores temporários (substitutos e bolsistas de pós-doutorado) deve constar em tabela própria, acompanhada dos comentários que se fizerem necessários.

Discentes serão apresentados através do número de matriculados por curso no biênio anterior aos anos de elaboração do PDU. São indispensáveis as informações sobre o número total de diplomados, e é recomendável a inclusão de dados de evasão e informações sobre o acompanhamento dos egressos.

O número de cotistas e o número de bolsistas de permanência, trabalho e atendidos pelos programas da Pró-Reitoria de Assuntos Estudantis podem ser incluídos ${ }^{15}$.

Por fim, será apresentado o quantitativo de trabalhadores e trabalhadoras terceirizados com a indicação das funções que desempenham na Unidade. Informações sobre o perfil profissional e sobre o nível de qualificação de terceirizados não são necessárias, sua inclusão fica a critério da Unidade.

Necessidades de captação de recursos humanos para o desenvolvimento das atividades próprias da Unidade devem ser apontadas no item 3.3.3 Ações, envolvidos, metas e indicadores.

\subsubsection{Levantamento da infraestrutura física}

Os PDUs devem apresentar a infraestrutura física à disposição da Unidade (salas, salas de aula, da direção, dos professores, secretaria, laboratórios, biblioteca) dividida em duas categorias: espaços físicos de uso exclusivo e espaços compartilhados.

Este levantamento se dará mediante apoio da Coordenação de Desenvolvimento do Plano Diretor (CDPD) ${ }^{16}$ e da Seção de Alocação e Compartilhamento de Espaços (SACE) ${ }^{17}$, por meio do Inventário do Espaço Físico da UFPel, e permitirá à Unidade planejar o atendimento de necessidades infraestruturais de curto prazo.

Comentários acerca da adequação dos espaços às atividades neles desenvolvidas podem ser incluídos neste tópico da análise, mas mudanças a serem efetivadas no próximo biênio precisam constar no item 3.3.3 Ações, envolvidos, metas e indicadores.

\subsubsection{Relação e descrição dos cursos ofertados}

Caso a Unidade Administrativa não ofereça cursos de nenhuma natureza é importante informar explicitamente a não aplicabilidade do item.

As Unidades Acadêmicas e Administrativas irão apresentar a relação dos cursos ofer-

15 Considerando dados quantitativos fornecidos pela Pró-Reitoria de Assuntos Estudantis (PRAE-UFPel) e revisados pela própria Unidade. Maiores informações e contato: https://wp.ufpel.edu.br/prae/.

16 Vinculada à Pró-Reitoria de Planejamento e Desenvolvimento (PROPLAN). Maiores informações em: http:// wp.ufpel.edu.br/proplan/coordenacao-de-desenvolvimento-do-plano-diretor/contato-diretor/.

17 Vinculada à Superintendência de Orçamento e Gestão de Recursos da Pró-Reitoria de Planejamento (SOR-PROPLAN). Maiores informações em: http://wp.ufpel.edu.br/proplan/superintendencia-de-orcamento-e-gestao-de-recursos/contato-sor/. 
tados no ano que precede a execução do plano, sejam eles de graduação, pós-graduação, extensão ou capacitação, especificando turnos e discriminando o número de vagas ofertadas e ocupadas (número total de matriculados em cada curso).

Informações referentes ao quantitativo de cursos de graduação e pós-graduação serão fornecidas pela Pró-Reitoria de Gestão da Informação e Comunicação ${ }^{18}$, cabendo às Unidades descrevê-los e apontar aspectos relevantes ao planejamento e ao desenvolvimento institucional.

A previsão de criação de novos cursos no próximo biênio precisa constar no item 3.3.3 Ações, envolvidos, metas e indicadores.

\subsubsection{Relação dos projetos e programas (ensino, pesquisa, extensão, outros)}

Programas de Pós-Graduação são incluídos no item 3.2.7 Relação e descrição dos cursos ofertados, não cabendo sua inclusão neste tópico.

Os projetos e programas de ensino, pesquisa e extensão, além de quaisquer outros projetos e programas desenvolvidos pela Unidade, devem ser identificados e descritos.

As unidades administrativas, se tiverem projetos ou ações, também devem apresentá-los neste tópico.

Informações referentes ao quantitativo de projetos e programas integrados serão fornecidas pela Pró-Reitoria de Gestão da Informação e Comunicação ${ }^{19}$, cabendo à Unidade descrevê-los e apontar quaisquer de seus aspectos que se mostrem relevantes ao planejamento e ao desenvolvimento institucional.

Ao descrever projetos e programas importa comentar sua abrangência, quantificar envolvidos e atendidos evitando a personificação, preservando seu caráter institucional.

\subsection{Operacionalização}

\subsubsection{Métodos empregados}

Uma síntese da metodologia adotada pela Unidade para elaboração do PDU precisa constar. A escolha de métodos e ferramentas de planejamento é uma decisão que cabe à própria Unidade e deve levar em conta suas peculiaridades e características.

Referências, exemplos, e uma síntese acerca dos métodos e ferramentas de planejamento mais utilizados em universidades públicas brasileiras podem ser encontrados no item 6. Métodos e ferramentas de planejamento.

18 Vinculada à Pró-Reitoria de Gestão da Informação e Comunicação (PROGIC). Maiores informações em http:// wp.ufpel.edu.br/cpi/contato/.

19 Idem, ibidem. 


\subsubsection{Processos participativos}

A legitimidade e a viabilidade do PDU estão diretamente vinculadas ao sucesso dos meios de participação adotados em sua elaboração. Os processos participativos de cada Unidade precisam estar de acordo com suas práticas e rotinas.

A apresentação dos meios de participação utilizados na elaboração do Plano é fundamental. O planejamento da Unidade requer a colaboração dos diversos atores e atrizes que dela fazem parte e, por isso, é preciso informar como e quando as pessoas se envolveram na elaboração do Plano, quantificar a abrangência das consultas públicas, e avaliar a eficiência dos processos de participação adotados.

Sugere-se a inclusão de relatos sobre os eventos promovidos, meios de comunicação e consulta, apreciações acerca da adesão ao processo e da frequência das consultas realizadas, bem como da forma como as decisões foram tomadas.

Diferentes pontos de vista podem figurar no PDU, eles correspondem aos diferentes cenários ou diferentes apreciações da situação, e reduzem os efeitos da parcialidade que caracteriza qualquer diagnóstico.

\subsubsection{Ações, envolvidos, metas e indicadores}

As metas e o cronograma podem ser apresentados em formato de quadro, facilitando a visualização e o acompanhamento da execução. Veja métodos para isso no item 6 . Métodos e ferramentas de planejamento.

As medidas a serem adotadas pela Unidade no decorrer da execução do Plano devem ser enumeradas de modo explícito, com nitidez e detalhamento. Este item é de enorme importância, pois nele são justificadas todas as propostas de mudança, apontando o que deve ser feito, a quem se atribui cada atividade prevista, quais metas devem ser alcançadas, e quais indicadores permitem avaliar a eficácia de cada ação. Para tanto, é preciso considerar a viabilidade do que está sendo planejado, e apresentar as ações planejadas em ordem de prioridade.

Em processos de planejamento, indicadores, metas e objetivos estão imbricados. Se os indicadores são recursos metodológicos que informam acerca do desenvolvimento de um aspecto analisado, cabe às metas a função de sinalizar se os objetivos traçados foram atingidos, ou seja, se os problemas e desafios identificados e propostos foram superados e cumpridos de fato.

Muito diversificadas serão as ações a serem incluídas neste tópico, desde melhorias nas rotinas administrativas, ou iniciativas de capacitação de servidores, até a ampliação de áreas verdes ou a adequação de espaços de convivência, por exemplo. Tudo o que possa resultar num melhor desempenho das atividades próprias da Unidade pode fazer parte do plano e deve figurar como ação específica neste tópico.

Quaisquer necessidades futuras aqui apresentadas precisam ser fundamentadas ${ }^{20}$. Recomenda-se que o conjunto de ações planejadas seja organizado nos mesmos cinco grandes temas do PDI-UFPel: 1. gestão institucional; 2. gestão acadêmica (ensino, pesquisa e extensão); 3. assistência estudantil, 4. gestão de pessoas e 5. infraestrutura. 
Convém observar que demandas relativas ao quinto tema (infraestrutura) devem ser condizentes com a otimização do uso dos espaços e seu compartilhamento. O planejamento de ações infraestruturais precisa estar em consonância com diretrizes de ampliação e qualificação dos espaços físicos para o próximo biênio, a serem definidas nos PDUs das Pró-Reitorias Administrativa e de Planejamento e Desenvolvimento ${ }^{21}$ e ambas podem ser consultadas oportunamente.

Sugere-se a composição de um quadro com o conjunto das ações previstas, indicando no mesmo os envolvidos em cada ação, as metas que se espera atingir e os indicadores que permitirão aferir se os objetivos foram alcançados, se as ações tiveram êxito.

Por "envolvidos" entende-se o conjunto dos órgãos, coletivos e pessoas responsáveis por executar uma determinada ação.

Metas qualitativas, quantitativas ou quali-quantitativas, correspondem a um ponto de chegada. Tão importante quanto justificar as ações é definir metas que lhe sejam compatíveis, levando em conta os recursos humanos, infra-estruturais e orçamentários disponíveis, e execução do PDU em curto prazo (dois anos ou quatro semestres letivos).

Para que ações possam ser adequadamente planejadas, atendendo aos interesses institucionais, é de grande importância o uso de indicadores de desempenho, que envolvem variáveis destacadas da integralidade das operações, escolhidas de acordo com a análise que se pretende realizar, e com os dados dos quais se pode dispor.

A escolha de indicadores deve privilegiar aqueles propostos pelo Fórum Nacional de Pró-Reitores de Planejamento e Administração e maiores informações podem ser encontrados no item 4. Indicadores deste guia.

\subsubsection{Cronograma de execução}

Para que o planejamento da Unidade seja executado sem atrasos, e para que todos os envolvidos estejam cientes do andamento das medidas, é imprescindível estabelecer um calendário de execução para as atividades previstas.

Sugere-se que o cronograma de execução considere o calendário acadêmico da UFPel, evitando o planejamento de atividades no decorrer dos recessos acadêmicos, a concentração de ações em fins-de-semestre ou em datas nas quais o acúmulo de funções administrativas é recorrente.

\subsubsection{Quadro Lógico}

A existência de cronograma e quadro de Ações, envolvidos, metas e indicadores (itens 3.3.3 e 3.3.4 deste guia) não exclui a necessidade de sintetizar o PDU em um Quadro Lógico de fácil compreensão, adequado à ampla divulgação.

Com a finalidade de divulgar o planejamento da Unidade, relacionando os objetivos a serem alcançados, sua articulação com a missão e a visão da UFPel e o conjunto completo das ações planejadas, um Quadro Lógico ou LFA (Logical Framework Approach) deve ser elaborado.

21 Por esse motivo, haverá uma rodada de cotejo dos Planos ao final do período de elaboração. 
O Quadro Lógico é uma síntese do plano de ações, na qual é possível encontrar o compromisso da Unidade com a Missão e a Visão institucionais, identificar rapidamente os principais aspectos da realização do Plano, mudanças esperadas, problemas específicos e metas a serem alcançadas. O principal propósito do Quadro é apresentar, já na fase de planejamento, as atividades previstas, suas etapas e seu alcance, relacionando as diversas variáveis envolvidas em uma mesma matriz de relações.

Para a construção do Quadro Lógico é possível utilizar do processo de Planejamento por Projeto Orientado para Objetivos, conhecido pela sigla ZOPP (Zielorientierte Projektplanung). Desenvolvido pela Agência Alemã de Cooperação Técnica (GTZ)22, o enfoque ZOPP adapta o Logical Framework Approach (LFA) para meios nos quais existem múltiplos interessados:

\begin{abstract}
A inovação do ZOPP em relação ao LFA é que o método ZOPP utiliza o instrumento de forma participativa. Para isso são aplicadas técnicas de trabalho chamadas moderação (também conhecida como facilitação), que permitem uma maior compreensão dos conteúdos trabalhados, especialmente por meio da visualização em workshops e, com isso, uma melhor comunicação entre os envolvidos ${ }^{23}$.
\end{abstract}

Em sua construção e em seu desenvolvimento, o enfoque de ZOPP procura estabelecer um ambiente de efetiva participação por meio de uma boa comunicação, o que se mostra compatível com outras ferramentas e métodos de planejamento ${ }^{24}$.

\title{
3.3.6 Meios de avaliação e de divulgação dos resultados
}

O PDU deve apresentar quais métodos de avaliação serão utilizados no acompanhamento de sua execução, bem como de que forma os resultados alcançados serão divulgados na Unidade e para a universidade e sociedade.

A escolha de métodos e instrumentos de avaliação e divulgação cabe à própria Unidade e deve levar em conta a natureza das ações planejadas, características e peculiaridades de sua comunidade acadêmica.

\subsection{Protocolo final}

\subsubsection{Referências}

Neste item devem constar as referências bibliográficas, testemunhais e documentais de toda a ordem que venha a ser utilizadas na elaboração do PDU. A lista resultante e suas citações, em nota ou no corpo do texto do Plano, devem estar de acordo com o Manual de Normas da UFPel25.

22 PFEIFFER 2000, p. 82.

23 Idem, ibidem.

24 Para Carlos Matus, por exemplo, "há alguns métodos simples de planejamento muito úteis, em minha opinião, para tratar de problemas parciais, um por um, que são adequados para trabalhar na base social, na qual os problemas são menos complexos e menos interrelacionados" (2007, p. 36). Dentre tais métodos, Matus destaca o enfoque ZOPP, reconhecendo que sua aplicação é adequada àquelas circunstâncias para as quais o Plano Estratégico Situacional se mostra excessivamente complexo.

25 Disponível em <http://wp.ufpel.edu.br/sisbi/normas-da-ufpel-para-trabalhos-academicos/>. No caso de dúvidas específicas: ASSOCIAÇÃO BRASILEIRA DE NORMAS TÉCNICAS. NBR 14724: Informação e documentação - Trabalhos acadêmicos - Apresentação. Rio de Janeiro: ABNT, 2006. 


\subsubsection{Anexos}

Conjunto de todo o material não elaborado para o PDU mas que se mostre indispensável à sua compreensão. Tal como ocorre com outros elementos pré-textuais e pós-textuais, a incorporação de anexos deve estar de acordo com o Manual de Normas da UFPel ${ }^{26}$. Cada documento em anexo será identificado por uma letra, subsequente à palavra "Anexo", centralizada no alto da página. A mesma nomenclatura será utilizada toda vez que o documento for mencionado no texto do Plano.

\subsubsection{Créditos}

Espaço destinado à creditação de todas as pessoas envolvidas na produção do PDU. Recomenda-se a atribuição de partes do documento aos seus respectivos redatores e redatoras, a identificação de proponentes de ações, apoiadores externos, membros de comissões de sistematização, etc. 


\section{Indicadores}

Indicadores são recursos metodológicos que informam acerca do desenvolvimento de um aspecto da realidade observada, por isso podem servir de parâmetro para propostas de transformação, ou para decisões de gestão. Não sendo classificatórios, revelam tendências, apontam a melhora ou a piora de fatores relevantes à análise de uma dada situação.

Há uma relação de necessidade entre dados, informações e indicadores, mas é importante não confundi-los. Enquanto um dado é "uma informação disponível, mas ainda não organizada ou manipulada (...). Pode ser um número, uma imagem, um som, um vídeo ou alguma outra mídia", uma informação é "um dado que já passou por um primeiro nível de organização, de acordo com um interesse específico". Por sua vez, um indicador é "uma variável crítica, que precisa ser controlada, mantida em determinados patamares"27.

Tais definições permitem concluir que "se uma variável não for crítica, então para você não é um indicador" e também que "um mesmo dado pode ser considerado um indicador ou uma simples informação, a depender de quem o vê" 28 .

Conjuntos de indicadores para o ensino superior foram estabelecidos e regulados pelo Ministério da Educação (MEC), pelo Tribunal de Contas da União (TCU) e pelo Fórum Nacional de Pró-Reitores de Planejamento e de Administração das Instituições Federais de Ensino Superior (FORPLAD). Recomenda-se que, em seus PDUs, as Unidades da UFPel possam privilegiar este último conjunto, recentemente atualizado em relatório disponível na página da PROPLAN-UFPel.

O MEC avalia regularmente as instituições de ensino superior a fim de acompanhar seu desenvolvimento, reconhecer méritos e orientar políticas de fomento. Suas avaliações baseiam-se principalmente em quatro indicadores (Conceito ENADE, IDD, CPC e IGC) que, operando de forma integrada, visam a fornecer regularmente um panorama da condição das instituições.

(a) Conceito ENADE é o indicador do Exame Nacional de Desempenho dos Estudantes, avalia a adequação do conhecimento discente com os parâmetros previstos nas diretrizes curriculares, tomando como base o desempenho no início e no fim do curso;

(b) IDD é o Indicador de Diferença entre os Desempenhos Observado e Esperado, visa a calcular o valor agregado pelo curso ao desenvolvimento discente, calculando a diferença entre o desempenho médio e o desempenho efetivo;

(c) CPC é o Conceito Preliminar do Curso, e estabelece um parâmetro de qualidade provisório, relacionando os números da instituição com os dos outros indicadores, podendo ou não ser confirmado com visitas de avaliadores;

(d) IGC é o Índice Geral de Cursos Avaliados da Instituição, um indicador de qualidade mais abrangente. Considera o CPC dos últimos três anos, relacionando-o com as avaliações da CAPES e a distribuição dos estudantes nas diversas modalidades de ensino.

Por sua vez, o Tribunal de Contas da União (TCU) orienta a inclusão de um conjunto de indicadores no Relatório Anual de Gestão das universidades federais, apresentando-os como im-

27 UCHÔA 2013, p. 7.

28 Idem, ibidem. 
portantes instrumentos de auxílio às decisões institucionais. No entanto, o TCU reconhece as limitações impostas pela simplicidade de seus indicadores frente à heterogeneidade das instituições.

A razão de existir dos indicadores do TCU está calcada no estabelecimento de uma série histórica do desenvolvimento das instituições, acompanhando a progressão de aspectos importantes para o estudos e a definição de ações específicas que possam contribuir na superação de problemas ou gerar aperfeiçoamentos. Ao todo, são doze os indicadores do TCU, abrangendo qualificação docente, relação numérica entre servidores e entre estes e os estudantes, custo do aluno, envolvimento com a pós-graduação, número de diplomados em relação ao número de ingressantes, percurso acadêmico dos estudantes e qualidade da pós-graduação. Não há neste conjunto nenhum indicador referente à extensão e aos cursos de especialização, recomendando o estudo e adoção de indicadores verificáveis e confiáveis quanto à representação dessas atividades.

O Fórum Nacional de Pró-Reitores de Planejamento e Administração (FORPLAD), ligado à Associação Nacional dos Dirigentes das Instituições Federais de Ensino Superior (ANDIFES), constitui um espaço de permanente diálogo entre os responsáveis pelo planejamento e administração das Instituições Federais de Ensino Superior. Busca encontrar soluções a problemas comuns de planejamento e administração universitária, fomentar o debate interinstitucional, assessorar os gestores e encaminhar propostas à ANDIFES.

O Fórum construiu e disponibilizou, em 2015, um conjunto amplo de indicadores, com a finalidade de estimular o uso de informações facilitadoras do acompanhamento de ações e do alcance de objetivos definidos em cada IFES ${ }^{29}$.

Para tanto, é necessário que os indicadores reflitam um contexto, pois são múltiplos os aspectos que impactam o alcance de objetivos institucionais. A compreensão da realidade, portanto, requer não um, mas uma série de indicadores cuja escolha deve integrar o planejamento e envolver seus atores de forma significativa e relevante. Sendo assim, a escolha de indicadores deve ser compreendida e partilhada pelos sujeitos das ações. As informações oriundas de indicadores precisam ser valorizadas na avaliação do plano e na tomada de decisões.

Recentemente, o FORPLAD sugeriu mudanças nos indicadores exigidos pelo Tribunal de Contas da União nos Relatórios de Gestão das IFES. Essas sugestões pretendem que os indicadores adotados reflitam melhor as questões essenciais das universidades públicas, como a qualificação de pessoal e dos cursos, o envolvimento com atividades de pesquisa e extensão, bolsas de desenvolvimento acadêmico, assistência ao estudante, evasão, retenção, controle de resíduos perigosos e comprometimento orçamentários com serviços terceirizados.

A eleição dos indicadores sugeridos foi orientada pelos seguintes critérios: (1) capacidade do indicador de representar a realidade, de forma confiável; (2) capacidade de ação do gestor para melhorar a situação informada pelo indicador; e (3) produção de informação relevante para melhorar a qualidade do gasto e/ou dos serviços.

Cabe enfatizar que a escolha de indicadores é, essencialmente, um ato que deve ser dos autores do planejamento. Critérios propostos e referidos podem inspirar a criação de novos indicadores ou aperfeiçoar os existentes, podendo contribuir para ações de planejamento e gestão em maior escala.

29 Para acessar os indicadores da FORPLAD basta seguir o link: http://www.forplad.andifes.org.br/cadastro1/textos/ indicadores/Indicadores-FORPLAD.pdf. 


\title{
5. Recomendações importantes
}

\begin{abstract}
Embora não seja o centro promotor de renovação social, a universidade pode representar um papel da maior importância em sua concretização. Entretanto, só poderá consegui-lo na medida em que unificar seus corpos docente[,técnico] e discente em torno de um conjunto de normas operacionais. Entre outras, destacam-se a tolerância política e ideológica; a defesa ativa da solidariedade acadêmica e, sobretudo, a preocupação permanente de manter a universidade funcionando, mesmo porque, só assim será possível fazê-la ouvida e exercendo influência na comunidade universitária e sobre outras instituições.
\end{abstract}

Darcy Ribeiro (1922-1997) ${ }^{30}$.

Antes do início da elaboração do PDU, é recomendável que o processo seja amplamente divulgado com ênfase no cronograma de atividades. Assim, a comunidade acadêmica ou administrativa estará ciente e apta a discutir e participar, como e quando mais lhe interessar.

Recomenda-se também que a redação do PDU seja feita com nitidez, originalidade e transparência, dando ênfase aos processos participativos, evitando a utilização de informações duvidosas, e creditando ideias, sugestões e propostas a seus enunciadores, sempre que possível.

Toda a documentação escrita ou imagética empregada na construção do documento deve ser devidamente referenciada, o que pode se estender para testemunhos orais de servidores(as) ativos(as) ou aposentados(as), alunos(as) e ex-alunos(as).

A construção do PDU como um documento de planejamento, deve atentar à realidade cultural e socioeconômica da Unidade, não omitindo, nem minimizando sua inserção na UFPel, na região, no país, ou além fronteiras. Quatro aspetos dos processos de planejamento ${ }^{31}$ merecem a atenção das redatoras e redatores do PDU: o contexto social, político e econômico deve ser evidenciado; tendo isso como base, as propostas de ação serão projetadas; estratégias precisam ser montadas visando o enfrentamento ou a aliança, fatores e atores externos e internos; e principalmente, o momento certo de agir deve ser escolhido, incluindo possibilidades de mudança de atitude e de estratégia ao longo do processo. 


\section{Métodos e ferramentas de planejamento}

A metodologia de planejamento a ser mobilizada no PDU deve estar de acordo com os desejos e as necessidades dos atores e atrizes envolvidos, dotados da liberdade e da responsabilidade de planejar, levando em conta as características e especificidades de sua Unidade. Assim, é preciso observar que

\footnotetext{
Fazer planejamento é, então, fazer política a partir do momento em que se escolhe como se quer planejar. "Como" se quer planejar, "quem" vai planejar e "o que" (qual a agenda) se vai planejar dão, de saída, a medida do método escolhido pelo ator que enuncia o desejo de planejar ${ }^{32}$.
}

A seguir, serão apontadas algumas sugestões metodológicas considerando as características da UFPel e os desafios peculiares ao planejamento universitário. Em estudo do Fórum Nacional de Pró-Reitores de Planejamento e Administração (Forplad) no ano de 2016, foram levantados os métodos de planejamento estratégico mais utilizados em instituições de ensino superior brasileiras, resultando no gráfico abaixo:

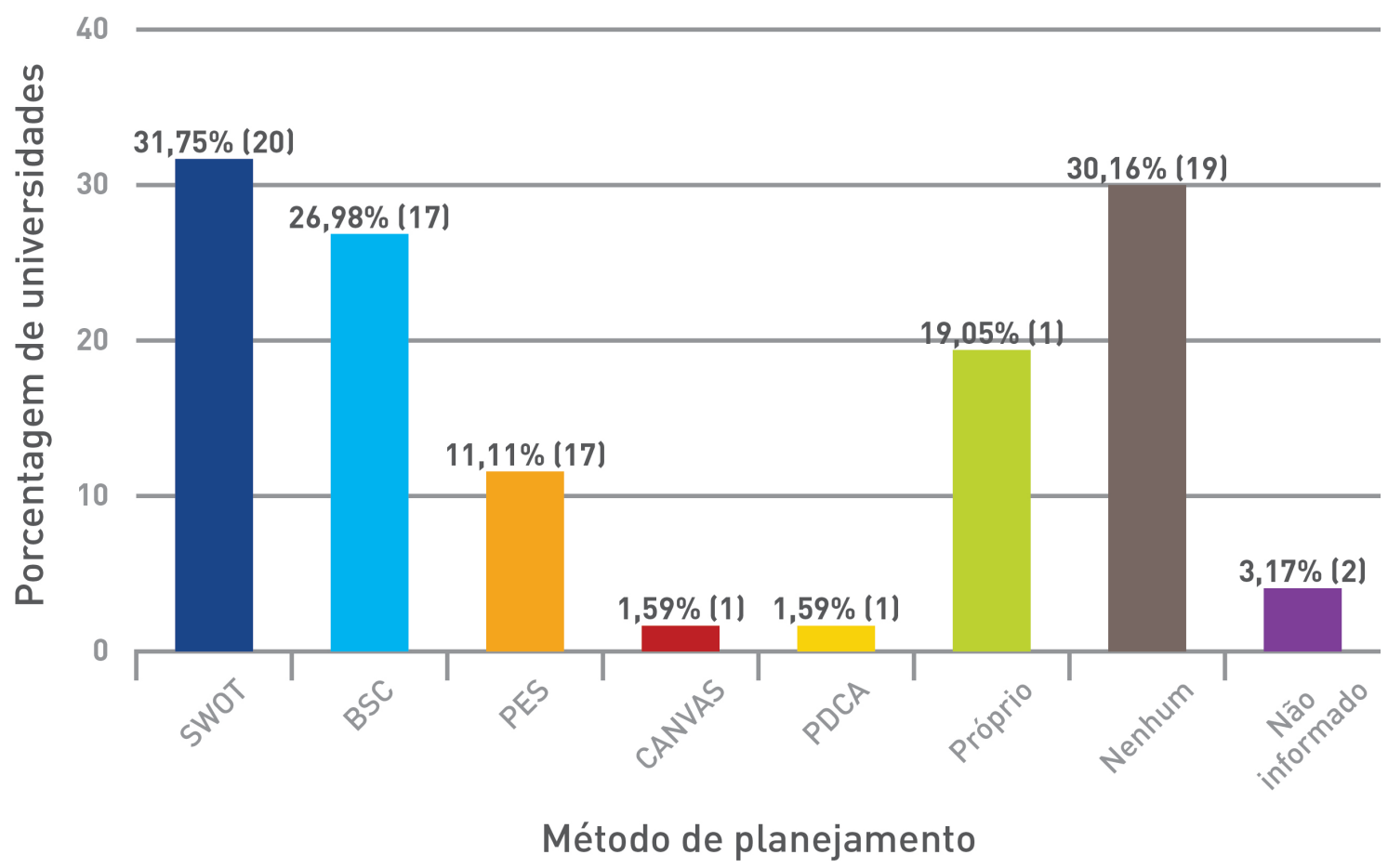

Fonte: Fórum Nacional de Pró-Reitores de Planejamento e Administração (2016) ${ }^{33}$.

\subsection{Análise SWOT ou FOFA}

No PDU, cada Unidade precisa apresentar suas principais características, as quais serão identificadas de forma participativa, envolvendo uma grande diversidade de atores e atrizes. Sugere-se, nessa etapa, a utilização da matriz F.O.F.A. (Forças, Oportunidades, Fraquezas, Ameaças) ou SWOT (Strengths, Weaknesses, Opportunities, Threats), como instrumento de análise facilitador desse levantamento. A ferramenta permite uma análise dos ambientes externo e interno, possibilitando a realização de um diagnóstico situacional, ou seja, uma "fotografia" das condições da Unidade, num dado momento. 
A FOFA distingue a identificação de fraquezas e forças, no âmbito interno, das oportunidades e ameaças externas, de modo que todas as condições e características levantadas possam ser expostas, de acordo com o quadro demonstrativo abaixo ${ }^{34}$.

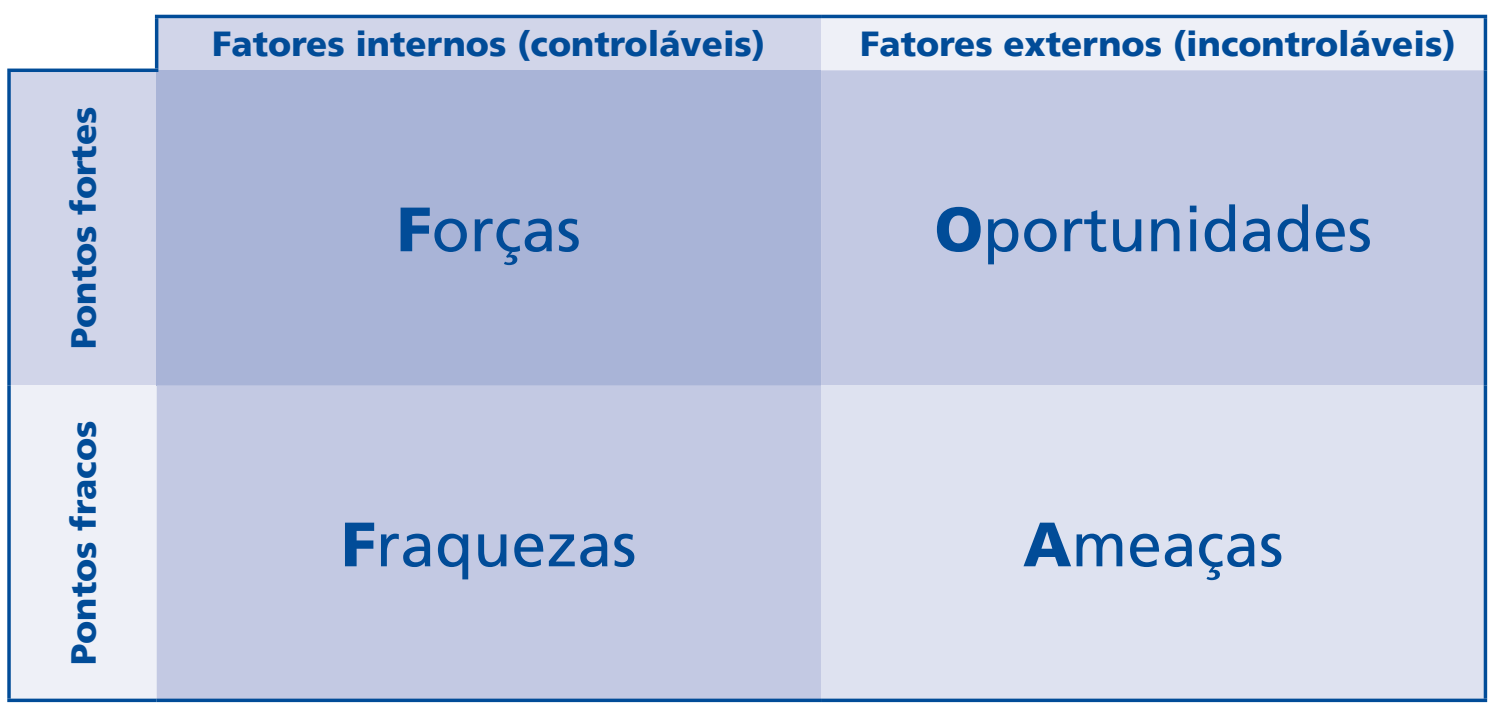

\subsection{Tableau de Bord ${ }^{35}$ e Balanced Scorecard ${ }^{36}$}

O Tableau de Bord (TB), ou Quadro de Instrumentos, é uma ferramenta de planejamento de origem francesa que permite rápida compreensão da situação, servindo de base para tomadas de decisão.

A análise por meio do TB se baseia principalmente em indicadores definidos e condizentes com os objetivos traçados. De acordo com Fagundes et al (2007, p. 3), o desenvolvimento da ferramenta é baseado em cinco ideias essenciais:

- É uma ferramenta de ajuda durante o processo de tomada de decisões;

- Tem um desenho simples e eficaz;

- Aglutina indicadores financeiros e não financeiros;

- É flexível diante dos câmbios e evolução de seu entorno; e

- Gera motivação a todos os níveis de responsabilidade.

O TB poderá ser elaborado de acordo com a identidade de cada Unidade, criando um quadro que exponha os principais objetivos de seu PDU, bem como seus indicadores.

O Balanced Scorecard (BSC) ${ }^{37}$ é muito semelhante ao TB, também se constitui a partir de um conjunto de indicadores que permitem visão geral e distinta da situação, mas é

34 Maiores informações sobre a matriz SWOT podem ser encontradas em: Kaplan, R. S., \& Norton, D. P. (2008). A execução premium: a obtenção da vantagem competitiva através do vínculo da estratégia com as operações do negócio. ( $2^{a}$ ed., A. C. da C. Serra, Trad.). Rio de Janeiro: Elsevier; ou em: http://www.revistargss.org.br/ojs/index. php/rgss/article/view/257/185, p 41 - 43.

35 Maiores informações sobre Tableau de Bord podem ser encontradas em: BOIX, Daniel; FÉMINIER, Bernard. Manager d'équipe. Le Tableau de Bord Facile. Éditions d'Organisation. Paris. 2004. Ou em: http://revistas.ufpr.br/rcc/ article/view/28110/19291.

36 Maiores informações sobre Balanced Scorecard podem ser encontradas em: KAPLAN, Robert S.; NORTON, David P. A estratégia em ação: balanced scorecard. Rio de Janeiro: Campus, 1997. 344 p. Ou em: https://www.researchgate.net/publication/28171171_Un_analisis_de_la_flexibilidad_del_Cuadro_de_Mando_integral_CMI_en_su_adaptacion_a_la_naturaleza_de_las_organizaciones.

37 O Balanced Scorecard é o método de planejamento atualmente (e amplamente) utilizado pelo CNPq como integrante de uma grande estrutura de planejamento, chamada de FIGE (Ferramentas Integradas de Gestão Estratégica) que orienta o funcionamento do órgão, inclusive a alta administração do mesmo. Maiores informações sobre isso podem ser encontradas em: CONSELHO NACIONAL DE DESENVOLVIMENTO CIENTíFICO E TECNOLÓGICO. Planejamento Estratégico 2025. Brasília: CNPq, 2014. 46 p. 
considerado um instrumento mais elaborado e completo.

Enquanto O TB mede os fatores chave, organiza grande parte das informações e seleciona os indicadores através da experiência, sem oferecer uma visão de toda a organização, o BSC é integrador, oferece uma visão de conjunto da organização, analisa e articula a gestão estratégica como um todo, seleciona os indicadores através de um método estruturado baseado em relações de causa e efeito ${ }^{38}$.

Cabe à Unidade definir qual instrumento se encaixa melhor na sua realidade e o quão enriquecedor e facilitador para o trabalho pode ser a sua adoção. Considerando que ferramentas como TB ou BSC podem contribuir significativamente na elaboração de quadros de ações pormenorizados ou sintéticos, ambos previstos na elaboração do PDU.

\subsection{Plano Estratégico Situacional (PES)}

O Planejamento Estratégico Situacional (PES) ${ }^{39}$ é uma "contraproposta epistemológica" 40 introduzida pelo economista chileno Carlos Matus como alternativa ao planejamento tradicional ou normativo. O PES se propõe a combater a improvisação ao mesmo tempo em que atribui flexibilidade ao plano de ação. Como ninguém detém todo o poder e surpresas podem acontecer, é preciso levar em conta várias possibilidades, cenários móveis e viabilidades transitórias que fazem do plano uma "aposta contra a incerteza" ${ }^{41}$.

Segundo Matus,

O irrealismo do planejamento tradicional baseia-se em uma só coisa que contamina toda a sua teoria com uma grande falta de rigor: ignora que o outro existe, ignora os adversários, ignora a metáfora do jogo e ignora os atores sociais. É o planejamento de um só ator e de muitos agentes. Esse pressuposto básico, que Ihe subtrai toda a representatividade do mundo real, cria uma deficiência que consiste na sua completa incapacidade de lidar com a incerteza e com as surpresas ${ }^{42}$.

No PES, os sujeitos envolvidos são atores e atrizes de um planejamento que parte do intercâmbio de problemas e valoriza regras de equidade. Ao dinamizar o processo e superar a rigidez das etapas comuns ao planejamento tradicional, o PES propõe quatro momentos distintos que podem ser descritos como:

$1^{\circ}$ - Explicativo: quando se explica como foram, são ou tendem a ser as ações, apreciando a situação e selecionando problemas.

$2^{\circ}$ - Prescritivo: seleção das ações necessárias para alcançar os objetivos propostos levando em consideração as incertezas e surpresas.

$3^{\circ}$ - Estratégico: elaboração das estratégias de incorporação das ações selecionadas considerando os diversos atores envolvidos, buscando tornar viável a implantação do que foi planejado.

$4^{\circ}$ - Tático-operacional: aplicação do plano, envolve colocar em prática as ações planejadas, mas não simplesmente executar, pois é preciso adaptar o que foi planejado às circunstâncias do momento ${ }^{43}$.

Para dar conta de variáveis não-predizíveis que estão fora do controle do ator que planeja, o PES propõe uma dualidade interna nos planos de ação, distinguindo as opera38 FAGUNDES et al, 2007.

39 Maiores informações sobre Planejamento Estratégico Situacional podem ser encontradas em: MATUS, Carlos; FRANCO, Huertas. O método PES: entrevista com Matus. Trad. Giselda Barroso Sauveur. São Paulo: Fundap, 2007. Ou em: http://produtos.seade.gov.br/produtos/spp/v05n04/v05n04_07.pdf.

40 CECILIO 2001, p. 3.

41 MATUS; HUERTAS 2007, p. 58.

42 Idem, p. 47.

43 MATUS 2006, p. 141-142; MATUS; HUERTAS 2007, p. 103-105. 
ções ${ }^{44}$, pelas quais os atores respondem integralmente, das demandas de operações e denúncias, cuja realização depende da "cooperação e decisão de outros atores" 45 .

Deste modo, o planejamento se faz a partir de razões técnicas e ideológicas, não desconsidera a dinâmica própria do jogo social e estabelece uma cultura participativa de planejamento com significativa complexidade.

Para enfrentar problemas menores, um modelo simplificado baseado no método PES foi elaborado. O Método Altadir de Planificação Popular (MAPP) se destinou a contextos de baixa complexidade, com menor possibilidade de ação independente dos atores e menor número de variáveis envolvidas. O MAPP visa a solucionar problemas no nível comunitário, a partir de técnicas de diálogo e etapas simples, evitando falhas de implementação de metodologias complexas por conta do pouco conhecimento específico dos atores.

São etapas do MAPP: a identificação e descrição dos problemas; a análise das causas e efeitos dos problemas; a definição de objetivos; a determinação dos pontos críticos; o desenho de ações que impactem os pontos críticos; a pressuposição dos recursos a serem aplicados para a execução das ações; a identificação dos atores chaves envolvidos no problema bem como em sua solução; a análise dos recursos de poder, com inclusão dos conceitos de peso, poder e força de cada ator; o desenho da trajetória temporal do plano; a análise da vulnerabilidade do plano; e a avaliação dos responsáveis e das operações ${ }^{46}$.

O PES é adotados em $11,11 \%$ das universidades federais brasileiras ${ }^{47}$. Experiências anteriores apontam para a necessidade de um "PES adaptado" às instituições universitárias ${ }^{48}$

\subsection{Ciclo PDCA}

O ciclo PDCA é uma ferramenta de gestão relacionada a programas de controle estatístico de qualidade ${ }^{49}$. Criado pelo físico e estatístico estadunidense Walter A. Shewhart (18911967) nos anos 1920, e propagado pelo estatístico William Edward Deming (1900-1993), o PDCA foi adotado em processos de desenvolvimento ao redor do mundo, sendo apropriado e readaptado em países como a Índia ${ }^{50}$ e o Japão ${ }^{51}$, destacando-se por estabelecer processos dinâmicos, que permitem identificar falhas e agir, baseados nas quatro fases sucessivas indicadas em sua nomenclatura: Planejar (Plan), Executar (Do), Verificar (Check) e Agir (Action).

$\mathrm{Na}$ fase de planejamento são definidos os objetivos, planos e diretrizes que serão adotados. A fase de execução é aquela em que se coloca em prática o que foi planejado, sendo recomendável a capacitação da equipe para que a mesma possa realizar os planos adequadamente. $\mathrm{Na}$ fase de verificação, acontece o confronto entre o que foi planejado e o que se realizou, de modo a poder avaliar a viabilidade da proposta inicial, verificando se ela está de acordo com as condições de realização. A fase de ação corresponde aos ajustes ou correções necessários para sanar eventuais problemas detectados na etapa anterior.

44 Segundo Matus, "uma operação é equivalente a uma jogada em um evento esportivo. É a unidade básica de ação que um ator realiza para mudar a realidade" (2007, p. 74).

45 MATUS; HUERTAS 2007, p. 70-71.

46 Maiores informações sobre MAPP podem ser encontradas em: MATUS, C. MAPP Método Altadir de Planificación Popular. Buenos Aires: Lugar Editorial, 2007.

47 Ver o gráfico do FORPLAD reproduzido neste guia, item 6. Métodos e ferramentas de planejamento.

48 Ver CECILIO 2001; HARDY; FACHIN 1996.

49 Maiores informações sobre PDCA podem ser encontradas em: WERKEMA, C. Métodos PDCA e DMAIC e suas Ferramentas Analíticas. Rio de Janeiro: Campus, 2012. Ou em: http://www.bibliotecas.sebrae.com.br/chronus/ARQUIVOS_CHRONUS/bds/bds.nsf/49B285DDC24D11EF83257625007892D4/\$File/NT00041F72.pdf.

50 MAHALANOBIS, 1948.

51 GITLOW, 1994. 
O PDCA destaca a característica "viva" dos processos de planejamento ao reconhecer que eles podem e devem ser revistos constantemente, na busca contínua por melhorar a qualidade. 


\section{Referências}

\subsection{Bibliografia}

CECILIO, L. C. de O. Pensando o Planejamento na Universidade. In: RAE Light v. 8, n.2. Abr./ jun. 2001, p. 2-7.

EPICURO, Carta sobre a felicidade (a Meneceu). Bilingue. Tradução de Álvaro Lorencini e Enzo Del Carratone. São Paulo: Editora da UNESP, 2002. 50 p.

FAGUNDES, J. A.; SOLER, C. C.; FELIU, V. M. R.; LAVARDA, C. E. F. Tableau de Bord vs Balanced Scorecard. Revista de Contabilidade do Mestrado em Ciências Contábeis da UERJ, Rio de Janeiro, v.12, n.1, p.1, jan./abril, 2007.

GITLOW, H. S. A Comparison of Japanese Total Quality Control and Deming's Theory of Management. The American Statistician, Vol. 48, No. 3 (Aug., 1994), pp. 197-203.

HARDY, C.; FACHIN, R. Gestão estratégica da universidade brasileira: teoria e casos. Porto Alegre: UFRGS, 1996.

MAHALANOBIS, P. C. Walter A. Shewart and Statistical Quality in India. Sankhya: The Indian Journal of Statistics (1933-1960), Vol. 9, No. 1 (Oct., 1948), p. 51-60.

MATUS, Carlos. O plano como aposta. In: GIACOMONI, James; PAGNUSSAT, José Luiz. (Org.). Planejamento e orçamento governamental; coletânea. Brasília: ENAP, 2006. p. 115-144.

MATUS, C.; HUERTAS, F. O Método PES - entrevista com Matus. São Paulo: Edições Fundap, 2007. 139 p.

RIBEIRO, D. A Universidade Necessária. São Paulo: Paz e Terra, 1975.

SILVA, F. L.. Universidade, Cidade, Cidadania. São Paulo: Hedra, 2014.

SILVEIRA, A.; PAIM, G.. Reforma Universitária: a política educacional brasileira do governo Castelo Branco a Costa e Silva (1964 - 1969). Cadernos FAPA, Porto Alegre, n² 2, p. $123-130$, 2005.

UNIVERSIDADE FEDERAL DO PARÁ. Coordenadoria de Modernização Administrativa. Guia para Elaboração de Plano de Desenvolvimento da Unidade. Belém, set. 2014. Disponível em <http://www.proplan.ufpa.br/>. Acessado em 11 de abril de 2017.

UCHOA, C. E. P. A. Elaboração de indicadores de desempenho institucional - Apostila. Brasília: Escola Nacional de Administração Pública (ENAP), 2013. Disponível em <http:// repositorio.enap.gov.br/bitstream/1/785/1/Elabora \%C3\%A7\%C3\%A30\%20de \%20Indicadores.pdf>. Acessado em 2 de outubro de 2017.

WERKEMA, C. Métodos PDCA e DMAIC e suas Ferramentas Analíticas. Rio de Janeiro: Campus, 2012. 


\subsection{Fontes documentais}

BRASIL. Decreto-lei $\mathbf{n}^{\circ}$ 750, de 8 de agosto de 1969. Diário Oficial, Brasília, DF, 11 de agosto de 1969. Seção 1, p. 1.

Tribunal de Contas da União. Orientações para o cálculo dos indicadores de gestão. Brasília, DF, mar. 2014. Disponível em: <http://portal.mec.gov.br/sesu/arquivos/pdf/ indicadores.pdf>. Acesso em: 12 agosto de 2017.

FÓRUM NACIONAL DE PRÓ-REITORES DE PLANEJAMENTO E DE ADMINISTRAÇÃO DAS INSTITUIÇÕES FEDERAIS DE ENSINO SUPERIOR. Comissão de Planejamento e Avaliação. Indicadores FORPLAD. Ouro Preto, 2015. Disponível em: <http://www.forplad.andifes.org.br/>. Acesso em: 12 de agosto de 2017.

INSTITUTO NACIONAL DE ESTUDOS E PESQUISAS EDUCACIONAIS ANÍSIO TEIXEIRA. Nota Técnica no 32/2017/CGCQES/DAES. Disponível em: <http://download.inep.gov.br/educacao_superior/enade/notas_tecnicas/2016/nota_tecnica_n32_2017_cgcqes_daes_calculo_conceito_enade.pdf>. Acesso em 01 de setembro de 2017.

Nota Técnica no 33/2017/CGCQES/DAES. Disponível em: <http://download.inep. gov.br/educacao_superior/enade/notas_tecnicas/2016/nota_tecnica_n33_2017_cgcqes_daes_ calculo_idd.pdf>. Acesso em 01 de setembro de 2017.

Nota Técnica n 38/2017/CGCQES/DAES. Disponível em: <http://download.inep. gov.br/educacao_superior/enade/notas_tecnicas/2016/nota_tecnica_n38_2017_cgcqes_daes_ calculo_cpc.pdf>. Acesso em 01 de setembro de 2017.

Nota Técnica n 39/2017/CGCQES/DAES. Disponível em: <http://download.inep. gov.br/educacao_superior/enade/notas_tecnicas/2016/nota_tecnica_n39_2017_cgcqes_daes_ calculo_igc.pdf >. Acesso em 01 de setembro de 2017.

RODRIGUES, Milton Luís Bresque. Entrevista concedida a Bárbara Denise Xavier da Costa. Pelotas, 20 de julho de 2017 (inédito).

UNIVERSIDADE FEDERAL DE PELOTAS. Pró-Reitoria de Planejamento e Desenvolvimento. Anuário retrospectivo da UFPel 1969/1996. Pelotas: Departamento de Desenvolvimento Institucional, 2004. volumes 1, 2 e 3.

Pró-Reitoria de Planejamento e Desenvolvimento. Avaliação do Plano de Ação da UFPel - 1998. Pelotas: Ed. da Universidade, 1999. 87 p.

Pró-Reitoria de Planejamento e Desenvolvimento. Avaliação do Plano de Ação da UFPel - 1999. Pelotas: Ed. da Universidade, 2000. 123 p.

Pró-Reitoria de Planejamento e Desenvolvimento. Avaliação do Plano de Ação da UFPel - 2000. Pelotas: Ed. da Universidade, 2001. 320 p.

Pró-Reitoria de Planejamento e Desenvolvimento. Avaliação do Plano de Ação da UFPel - 2001. Pelotas: Ed. da Universidade, 2003. 216 p.

Pró-Reitoria de Planejamento e Desenvolvimento. Avaliação do Plano de Ação da UFPel de 2002. Pelotas: Ed. da Universidade, 2003. 215 p. 
Pró-Reitoria de Planejamento e Desenvolvimento. Avaliação do Plano de Ação da UFPel de 2003. Pelotas: Ed. da Universidade, 2004. 275 p.

Documento base para definição dos princípios orientadores da elaboração do projeto pedagógico, regimento e estatuto da UFPEL. Disponível em: <http:// wp.ufpel.edu.br/constituinte/2016/04/20/constituinte-propoe-principios-orientadores-paradocumentos/>. Acesso em 11 de setembro de 2017.

Estatuto da Universidade. Disponível em: <http://wp.ufpel.edu.br/scs/estatuto/>. Acesso em 06 de setembro de 2017.

Histórico. Disponível em: <http://portal.ufpel.edu.br/historico/>. Acesso em 13 de setembro de 2017.

Vice-Reitoria. Coordenação de Bibliotecas. Manual de normas UFPel para trabaIhos acadêmicos. Pelotas, 2013. Revisão técnica de Aline Herbstrith Batista, Carmen Lúcia Lobo Giusti e Elionara Giovana Rech. Disponível em: <http://wp.ufpel.edu.br/sisbi/normasda-ufpel-para-trabalhos-academicos/>. Acesso em: 11 de setembro 2017.

Página da Constituinte Universitária. Disponível em: <http://wp.ufpel.edu.br/ constituinte/>. Acesso em: 14 de setembro de 2017.

Pró-Reitoria de Planejamento e Desenvolvimento. Plano de Ação da UFPel - 1998. Pelotas: Ed. da Universidade, 1998. 106 p.

Pró-Reitoria de Planejamento e Desenvolvimento. Plano de Ação da UFPel - 1999. Pelotas: Ed. da Universidade, 1999. 122 p.

Pró-Reitoria de Planejamento e Desenvolvimento. Plano de Ação da UFPel - 2000. Pelotas: Ed. da Universidade, 2000. 287 p.

Pró-Reitoria de Planejamento e Desenvolvimento. Plano de Ação da UFPel - 2001. Pelotas: Ed. da Universidade, 2001. 199 p.

Pró-Reitoria de Planejamento e Desenvolvimento. Plano de Ação da UFPel de 2002. Pelotas: Ed. da UFPel, 2002. 164 p.

Pró-Reitoria de Planejamento e Desenvolvimento. Plano de Ação da UFPel de 2003/2004. Pelotas: Ed. da UFPel, 2003. 212 p.

PPI - Projeto Pedagógico Institucional UFPel. Pelotas, 2003 [1991]. Disponível em <http://wp.ufpel.edu.br/pdi/ppi-projeto-pedagogico-institucional/>. Acesso em: $17 \mathrm{de}$ novembro de 2017.

Regimento Geral da Universidade Federal de Pelotas. Disponível em: <http:// wp.ufpel.edu.br/scs/regimento/>. Acesso em: 01 de julho de 2017. 